\title{
Microscopía y Principales Características M orfológicas de Algunos Ectoparásitos de Interés Veterinario
}

\author{
Microscopy and Morphological Characteristics of Some Ectoparasites of \\ VETERINARY INTEREST
}
Adriana del Pilar Pulido-Villamarín',5, Rubiela Castañeda-Salazar', Humberto Ibarra- Ávila ${ }^{3}$, Luis David Gómez-Méndez ${ }^{2}$, Angélica María Barbosa-Buitrago ${ }^{4}$

\section{Resumen}

Los ectoparásitos afectan de manera importante el estado sanitario de los animales debido a que sus efectos exfoliatrices, tóxicos y alérgicos causan un detrimento en su bienestar y, adicionalmente, pueden tener un efecto negativo en los índices de conversión alimenticia en animales de producción. Las ectoparasitosis pueden afectar animales de todas las especies y edades; sin embargo, los jóvenes son los más susceptibles. La importancia de un adecuado diagnóstico de estos problemas sanitarios está dada no solo por la incomodidad que generan en sus hospederos, sino por la posibilidad que tienen de transmitir otros agentes patógenos. El objetivo del presente trabajo fue presentar imágenes donde se describen algunas características morfológicas de determinados ectoparásitos de interés en Medicina Veterinaria, especialmente bajo las condiciones de Colombia.

Palabras clave: diagnóstico, parásitos externos, microscopía óptica, microscopía electrónica de barrido

\section{Abstract}

The ectoparasites significantly affect the health status of the animals due to their toxic and allergic effects that cause a detriment in their welfare and additionally may have a negative effect on feed conversion rates in farm animals. Ectoparasites can affect animals of all species and ages, being the young animals the most susceptible. The importance of a proper diagnosis of these health problems is given not only by the

\footnotetext{
${ }^{1}$ Unidad de Investigaciones Agropecuarias -UNIDIA-, ${ }^{2}$ Grupo Biotecnología Ambiental e Industrial, Departamento de Microbiología, Facultad de Ciencias, Pontificia Universidad Javeriana, Bogotá DC, Colombia

${ }^{3}$ Corporación Micros, Villa Emilita, Chía, Cundinamarca, Colombia

${ }^{4}$ Universidad El Bosque, Bogotá DC, Colombia

${ }^{5}$ E-mail: adriana.pulido@javeriana.edu.co
}

Recibido: 23 de setiembre de 2014

Aceptado para publicación: 25 de setiembre de 2015 
discomfort they generate in their hosts, but by the fact that they can transmit other pathogens. The aim of this paper was to describe some morphological characteristics of specific ectoparasites that have veterinary importance, especially under the prevailing environmental conditions in Colombia.

Key words: diagnostic, external parasites, optical microscopy, scanning electronic microscopy

\section{INTRODUCCIÓN}

Los ectoparásitos se localizan en el tejido subcutáneo o en la superficie dérmica, pelaje o plumas de los hospederos (Balashov, 2006; Wall, 2007), donde se alimentan de descamaciones o de sangre, produciendo lesiones de forma directa. La mayoría pertenece al grupo de los artrópodos, donde las familias clínicamente implicadas en medicina veterinaria son Chelicerata (ácaros, garrapatas) y Mandibulata (insectos) (Cordero del Campillo et al., 1999; Balashov, 2006).

El mecanismo de acción patógena se basa en efectos sustractores o exfoliatrices, tóxicos, alérgicos y mecánicos (masticadores, hematófagos, etc) (Balashov, 2006). Por ejemplo, pueden producir reacciones inflamatorias con alopecia, formación de costras (Fig. 1), prurito y alergias en los hospederos, ya sea por los antígenos salivales o fecales del artrópodo; donde además existe la posibilidad de transmisión de diversos agentes infecciosos (Wall, 2007).

El diagnóstico depende, en todos los casos, de la obtención e identificación del parásito, sea mediante la observación directa macroscópica o mediante un raspado profundo de piel (Fig. 1B, C, D) y su visualización en el microscopio (Figs. 2 y 3) (Bergvall, 2005; Ballweber, 2006; Demeller et al., 2012).

En el caso de los ácaros, la zona de elección para la toma de muestra es la parte más húmeda del borde de la lesión, debido a que la mayoría de los ectoparásitos pueden encontrarse en las zonas periféricas de las le- siones activas. Debe usarse un bisturí afilado para raspar profundamente la parte externa de la dermis junto con las raíces de los pelos, donde la profundidad dependerá del inicio del sangrado. Para esto, conviene humedecer la piel con glicerina o aceite mineral para permitir que los ácaros se adhieran al bisturí y se evite la movilidad y su posible pérdida (Curtis, 2001; Ballweber, 2006). La muestra se recoge de forma directa en una lámina porta-objetos, en un tubo pequeño o en un frasco hermético; asimismo, si se sospecha de ectoparásitos en la oreja se debe obtener material escamoso del oído externo con un hisopo o un trozo de algodón sujetado con unas pinzas (Curtis, 2001; Ballweber, 2006).

El objetivo del presente trabajo fue presentar imágenes donde se describen algunas características morfológicas de determinados ectoparásitos de interés en medicina veterinaria que fueron obtenidas durante la práctica diaria, especialmente bajo las condiciones de Colombia.

\section{AlgunOs Ectoparásitos de IMPOR- TANCIA CLINICA VETERINARIA}

\section{Ácaros}

Los ácaros pertenecen al Phylum Arthropoda, Subphylum Chelicerata, clase Arachnida, subclase Acari. En el Superorden Anactinotrichida están los órdenes Ixodida y Mesostigmata, y en el Superorden Actinotrichida los órdenes Prostigmata, Astigmata y Oribatida. Asimismo, basados en la morfología de los artrópodos se reconocen ácaros sarcópticos y no sarcópticos, los pri- 

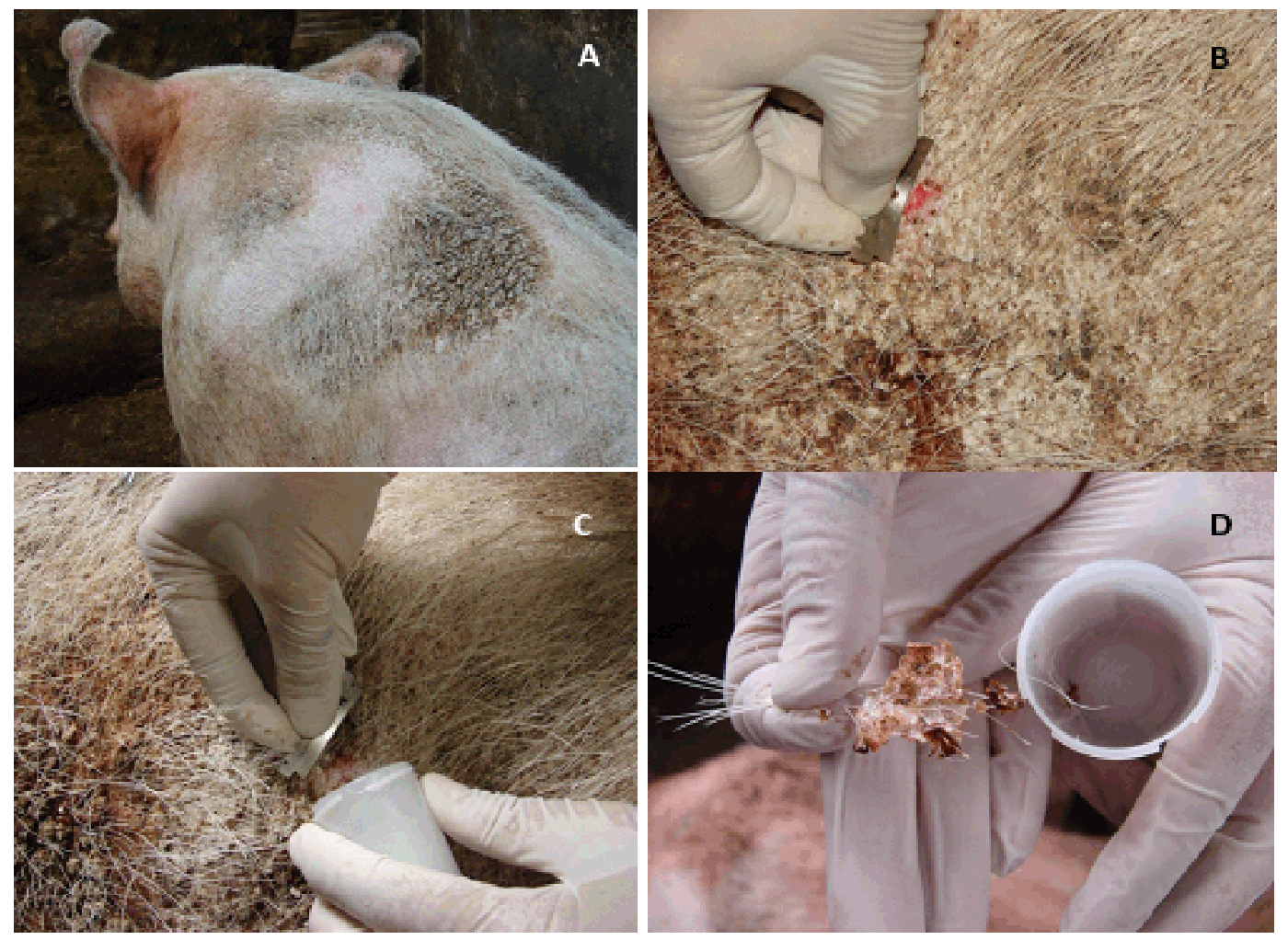

Figura 1. Lesiones cutáneas por ectoparásitos en el cerdo. A. Lesión costrosa en piel. B, C y D. Toma de muestras de piel para diagnóstico de laboratorio

meros con un cuerpo redondo a ovalado con extremidades articuladas, características opuestas al segundo grupo (Bergvall, 2005; Balashov, 2006). Dentro de cada orden se encuentran numerosas especies específicas de hospedero (Cuadro 1).

Su implicación en sanidad animal está dada por la incomodidad generada en el hospedero debida a la irritación, prurito y a las lesiones ocasionadas por la penetración subcutánea de los ácaros ante la creación de túneles en el estrato córneo de la piel, o como en el caso de Demodex gatoi por su localización en el estrato córneo. Adicionalmente, se presentan infecciones bacterianas secundarias (Cortinas y Jones, 2006; Saari et al., 2009; Hernández et al., 2010).

La transmisión ocurre por contacto directo con animales infectados o por medio de materiales contaminados como camas y pisos, así como de madres a sus crías durante el periodo de lactancia (Mullen y Durden, 2009; Saari et al., 2009; ESCCAP, 2012). El ciclo de vida de los ácaros puede durar cuatro semanas, incluyendo uno o varios estadios: huevo (eclosiona en 4 a 6 días), prelarva ( 3 a 6 días), larva ( 3 a 5 días), protoninfa (4 a 5 días), deutoninfa (6 a 10 días), tritoninfa y adulto. El desarrollo de huevo a adulto puede durar de 2 a 3 semanas. Los huevos pueden ser depositados externamente o son mantenidos en el útero de la hembra hasta la eclosión (Fig. 3).

El cuerpo del adulto está dividido en dos secciones: la sección anterior llamada gnatosoma y la sección posterior llamada idiosoma. El gnatosoma (Fig. 4A) consta de palpos (órganos sensoriales para estímulos químicos y táctiles), generalmente con cinco secciones, y quelíceros, empleados para la sujeción del alimento, con tres segmentos, que 
Cuadro 1. Especies comunes de ácaros y sus hospederos animales, reportadas en la literatura científica ${ }^{1}$

\begin{tabular}{|c|c|c|c|}
\hline Nombre científico & Nombre común & Hospedero & $\begin{array}{l}\text { Localización y } \\
\text { sintomatología }\end{array}$ \\
\hline $\begin{array}{l}\text { Chorioptes bovis } \\
\text { Chorioptes } \mathrm{sp}\end{array}$ & $\begin{array}{l}\text { Ácaro de la sarna } \\
\text { del ganado }\end{array}$ & $\begin{array}{l}\text { Bovinos, equinos, } \\
\text { ovinos }\end{array}$ & $\begin{array}{l}\text { En los espolones y la } \\
\text { base de la cola. Causa } \\
\text { inflamación y lesiones } \\
\text { escamosas. }\end{array}$ \\
\hline Dermanysus gallinae & $\begin{array}{l}\text { Ácaro rojo de las } \\
\text { gallinas } \\
\text { Acaro de las } \\
\text { palomas }\end{array}$ & $\begin{array}{l}\text { Aves de corral, } \\
\text { canarios, pericos, } \\
\text { palomas, humanos, } \\
\text { equinos, caninos, } \\
\text { felinos, roedores }\end{array}$ & $\begin{array}{l}\text { Mayormente en cabeza } \\
\text { y patas, donde se } \\
\text { desarrollan pápulas } \\
\text { pruriginosas y costras. }\end{array}$ \\
\hline $\begin{array}{l}\text { Demodex canis } \\
\text { Demodex cati } \\
\text { Demodex gatoi } \\
\text { Demodex bovis } \\
\text { Demodex caprae } \\
\text { Demodex aurati } \\
\text { Demodex criceti }\end{array}$ & $\begin{array}{l}\text { Ácaro folicular } \\
\text { Demodicosis }\end{array}$ & $\begin{array}{l}\text { Caninos, felinos, } \\
\text { ovinos, porcinos, } \\
\text { bovinos, caprinos }\end{array}$ & $\begin{array}{l}\text { Con mayor frecuencia } \\
\text { en cara y cuello. } \\
\text { Signos clínicos más } \\
\text { evidentes en caninos. } \\
\text { Causa diversos grados } \\
\text { de alopecia con o sin } \\
\text { descamación leve. }\end{array}$ \\
\hline $\begin{array}{l}\text { Sarcoptes scabiei } \\
\quad \text { var. bovis } \\
\quad \text { var. ovis } \\
\quad \text { var. aucheniae }\end{array}$ & $\begin{array}{l}\text { Ácaro de la sarna } \\
\text { Sarna sarcóptica } \\
\text { Sarna de la cabeza }\end{array}$ & $\begin{array}{l}\text { Caninos, ovinos, } \\
\text { caprinos, porcinos, } \\
\text { equinos, conejos, } \\
\text { roedores, especies } \\
\text { silvestres, alpacas, } \\
\text { llamas }\end{array}$ & $\begin{array}{l}\text { En zonas con poco } \\
\text { pelo, principalmente } \\
\text { en miembros } \\
\text { posteriores y abdomen. } \\
\text { Enrojecimiento de la } \\
\text { piel, pústulas, pápulas, } \\
\text { lesiones costrosas y } \\
\text { severo prurito. }\end{array}$ \\
\hline Notoedres cati & $\begin{array}{l}\text { Sarna notoédrica o } \\
\text { de la cabeza }\end{array}$ & & $\begin{array}{l}\text { Lesiones en orejas, } \\
\text { cara, cuello y } \\
\text { hombros, pudiendo } \\
\text { llegar al abdomen, } \\
\text { patas y periné. }\end{array}$ \\
\hline $\begin{array}{l}\text { Psoroptes equi } \\
\text { Psoroptes ovis } \\
\text { Psoroptes cuniculi }\end{array}$ & $\begin{array}{l}\text { Ácaros de la sarna } \\
\text { psoróptica }\end{array}$ & $\begin{array}{l}\text { Equinos, roedores, } \\
\text { bovinos, ovinos, } \\
\text { conejos }\end{array}$ & $\begin{array}{l}\text { Lesiones con inicio en } \\
\text { orejas, cara, cuello y } \\
\text { tronco. Causa prurito, } \\
\text { pápulas, alopecia, } \\
\text { excoriaciones, } \\
\text { supuración y costras. }\end{array}$ \\
\hline $\begin{array}{l}\text { Neotrombicula } \\
\text { autumnalis } \\
\text { N. alfreddugesi }\end{array}$ & $\begin{array}{l}\text { Ácaros de la } \\
\text { cosecha }\end{array}$ & Equinos & $\begin{array}{l}\text { Afecta cara, abdomen } \\
\text { y extremidades }\end{array}$ \\
\hline Otodectes cynotis & $\begin{array}{l}\text { Ácaro de la sarna } \\
\text { de la oreja }\end{array}$ & Caninos, felinos & $\begin{array}{l}\text { Inflamación del oído } \\
\text { externo, seborrea. }\end{array}$ \\
\hline
\end{tabular}

${ }^{1}$ Bergvall, 2005; Cortinas y Jones, 2006; Mullen y Durden, 2009; Demeler et al., 2012; George et al., 2015 


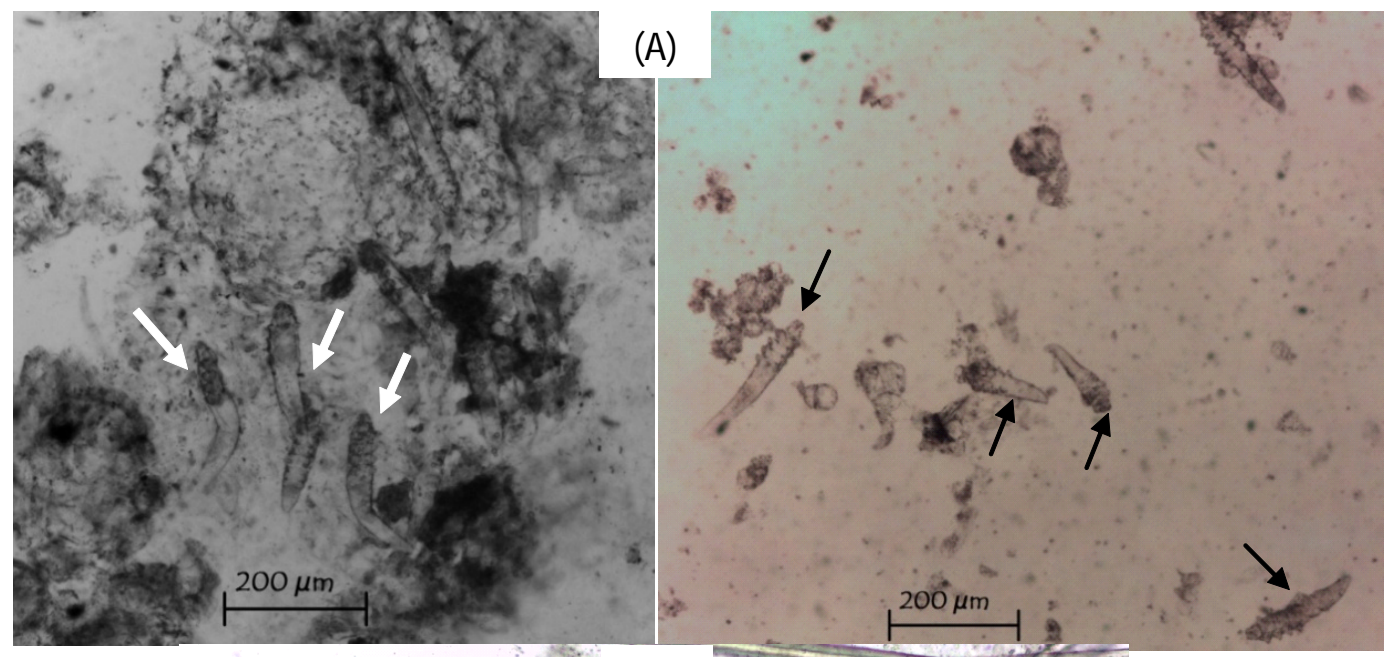

(B)

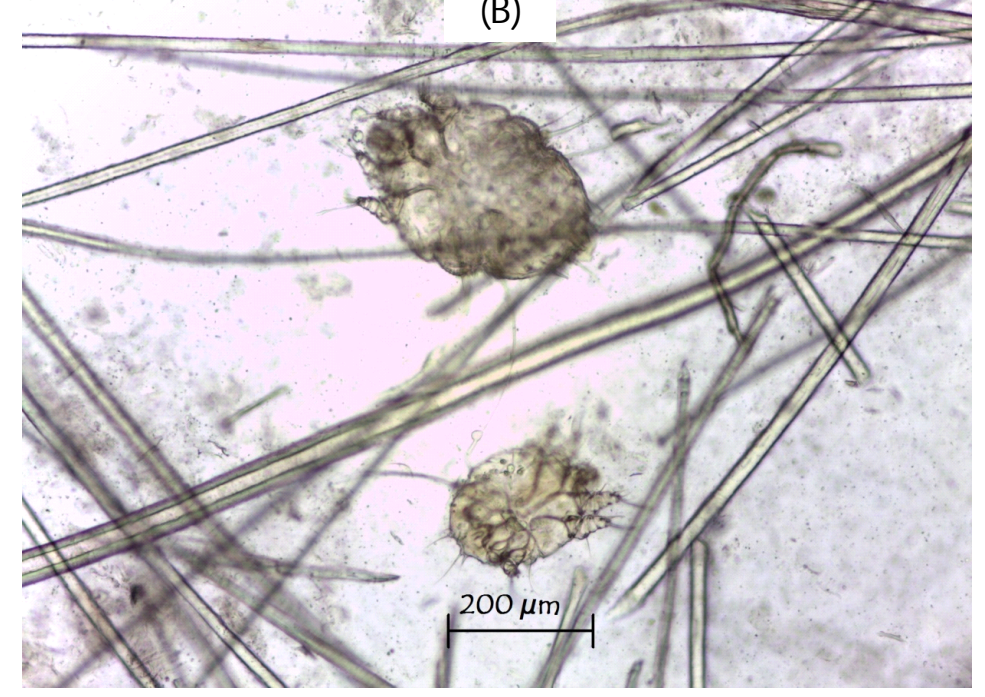

Figura 2. Examen directo de raspado cutáneo con infestación severa por (A) Demodex sp (flechas). 100x, y (B) presencia de Sarcoptes sp. 10x

terminan en la quela o pinza (Fig. 4B). Algunos presentan ciertas variaciones, por ejemplo, Psorosptes ovis posee además un hipostoma o 'subcapítulo' en forma de U (Demeler et al., 2012). El idiosoma está conformado por el podosoma (porción anterior del cuerpo conteniendo las patas), el opistosoma (región del cuerpo posterior a las patas), el propodosoma (dos primeros pares de patas) y el histerosoma (inicia en el tercer par de patas hasta finalizar el cuerpo) (Fig. 5A). Las patas se dividen en segmentos que termina en uñas o cerdas (Mullen y Durden, 2009).

Las larvas o estadios juveniles solo presentan tres pares de patas (Fig. 6A), mientras las protoninfas, ninfas y adultos presentan cuatro pares de patas (Fig. 6A, B).

Los ácaros del género Demodex (Fig. 7) presentan el cuerpo alargado a diferencia de los otros géneros. Asimismo, presentan patas (Fig. 7A) y quelíceros muy cortos (Fig. 7B). 


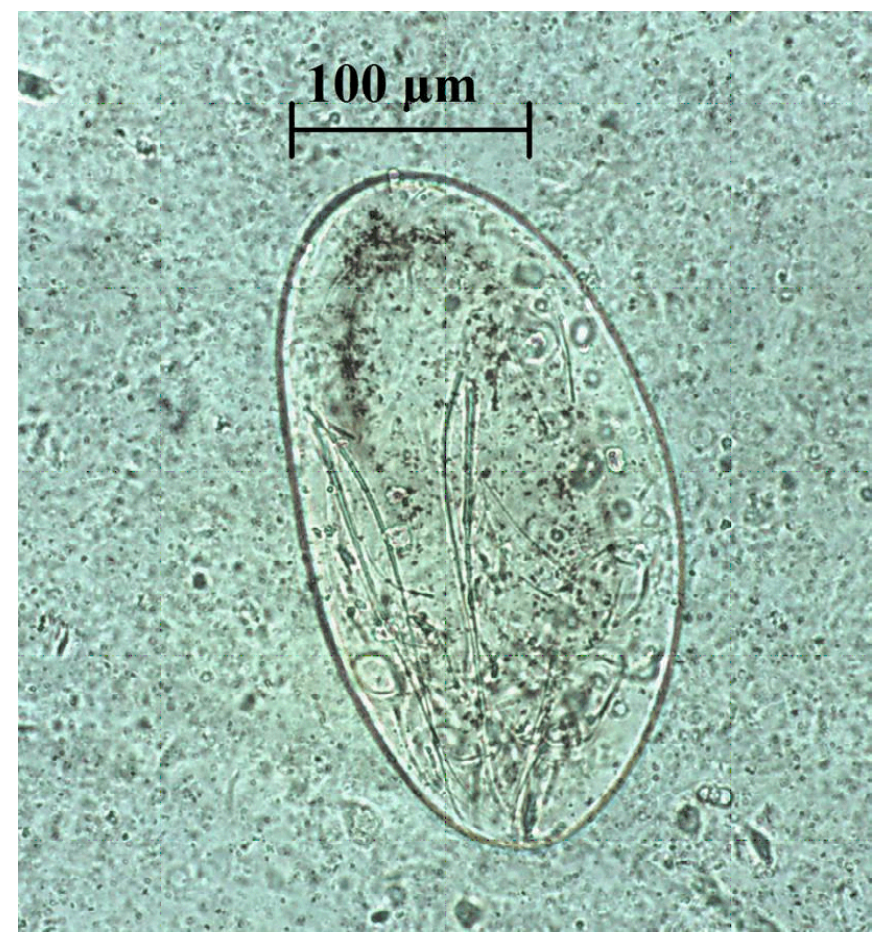

Figura 3. Huevo de Sarcoptes sp. 200x

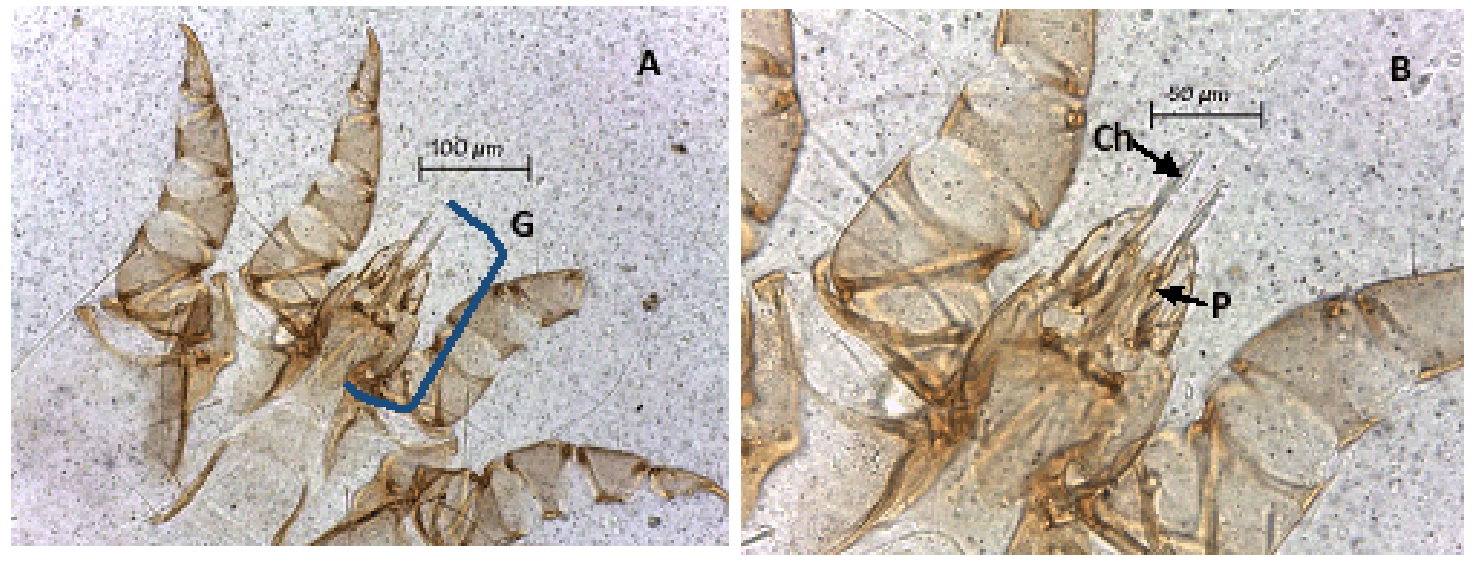

Figura 4. Psoroptes sp. (A) Gnatosoma [G] 200x. B. Gnatosoma: pedipalpos [P] y quelíceros [Ch]. 400x 

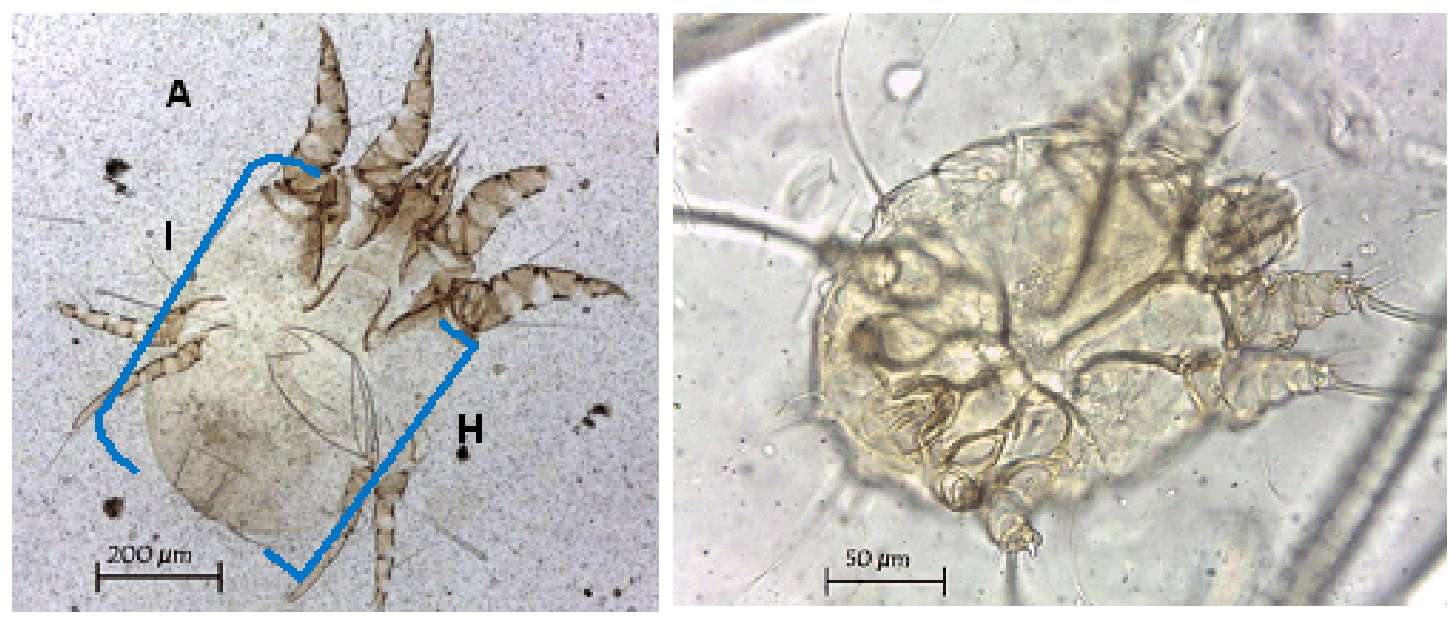

Figura 5. A. Psoroptes sp adulto: Idiosoma (I) e Histerosoma (H) (100x). B. Sarcoptes sp adulto $(400 \mathrm{x})$
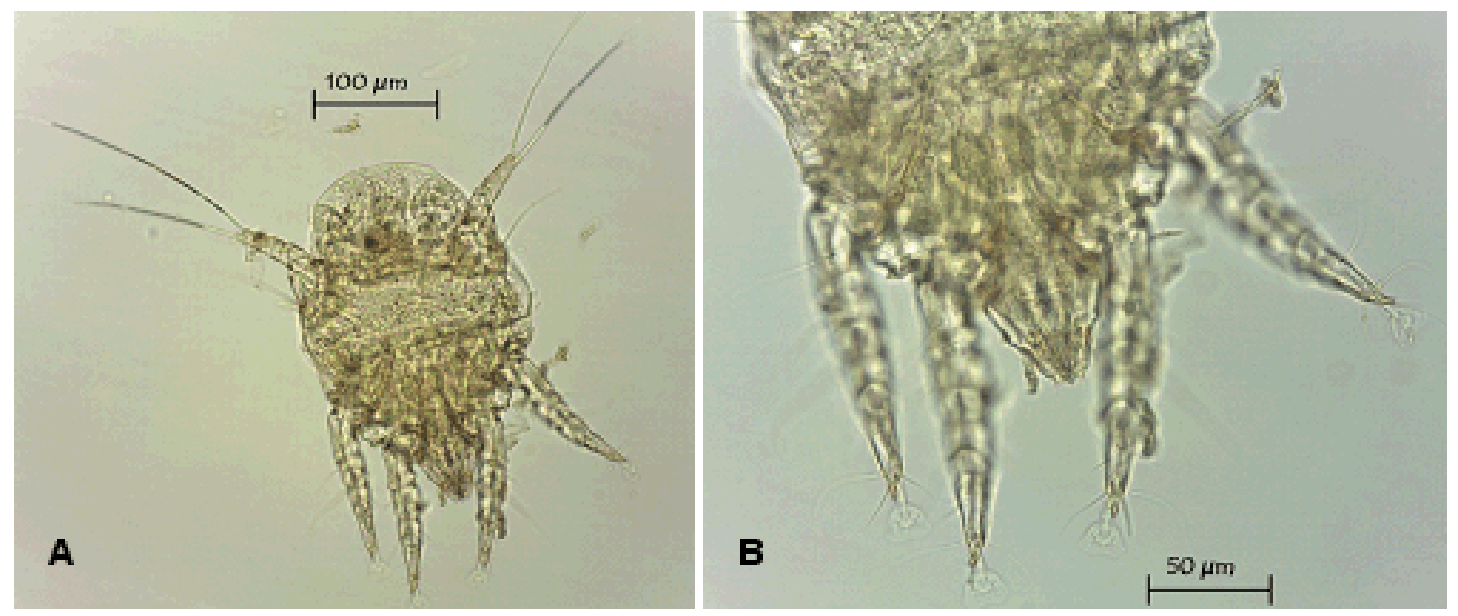

Figura 6. Otodectes sp. A. Estadio juvenil. 200x. B. Gnatosoma y patas. 400x

\section{Garrapatas}

Las garrapatas son ectoparásitos obligados de distribución mundial, que pertenecen al Phylum Arthropoda, Subphylum Chelicerata, clase Aracnida, subclase Acari, orden Acarina, suborden Ixodida (Metastigmata) y familias Argasidae (garrapatas blandas), Ixodidae (garrapatas duras) y Nutellidae (Cordero del Campillo et al., 1999; Cortinas y Jones, 2006; Stafford, 2007; Gunn y Pitt, 2012).
Se alimentan de sangre y necesitan de un hospedero animal (aves, reptiles, mamíferos e incluso en algunos casos anfibios) o humano para sobrevivir y reproducirse (Cuadro 2). Su importancia radica en que actúan como vectores de enfermedades virales, bacterianas (Rickettsia sp, Ehrlichia sp, E. ruminantium, Anaplasma marginale, Borrelia burgdorferi, Coxiella burnetii) y parasitarias (Babesia sp, Theileria cervi), tanto para los animales como para el humano (Cordero del Campillo et al., 1999; Cortinas 
Cuadro 2. Principales especies de garrapatas en hospederos animales ${ }^{1}$

\begin{tabular}{|c|c|c|}
\hline Hospedero & Especie & Nombre común \\
\hline Rumiantes & $\begin{array}{l}\text { Ixodes ricinus } \\
\text { Dermacentor marginatus } \\
\text { Rhipicephalus microplus } \\
\text { Rhipicephalus bursa } \\
\text { Rhipicephalus turanicus } \\
\text { Hyalomma marginatum } \\
\text { Hyalomma lusitanicum } \\
\text { Boophilus annulatus }\end{array}$ & Garrapata de la oveja \\
\hline Equinos & $\begin{array}{l}\text { Dermacentor nitens } \\
\text { Dermacentor marginatus } \\
\text { Dermacentor reticulatus } \\
\text { Dermacentor nitens } \\
\text { Hyalomma marginatum } \\
\text { Hyalomma lusitanicum } \\
\text { Haemaphysalis punctata } \\
\text { Rhipicephalus sanguineus } \\
\text { Rhipicephalus bursa } \\
\text { Boophilus annulatus }\end{array}$ & Garrapata parda \\
\hline Caninos y felinos & $\begin{array}{l}\text { Amblyomma americanum } \\
\text { Amblyomma cajennense } \\
\text { Amblyomma maculatum } \\
\text { Amblyomma variegatum } \\
\text { Dermacentor andersoni } \\
\text { Dermacentor variabilis } \\
\text { Dermacentor reticulatus } \\
\text { Ixodes canisuga } \\
\text { Ixodes haxagonus } \\
\text { Ixodes holocyclus } \\
\text { Ixodes pacificus } \\
\text { Ixodes persulcatus } \\
\text { Ixodes ricinus } \\
\text { Ixodes scapularis } \\
\text { Haemaphysalis leachi } \\
\text { Rhipicephalus sang uineus } \\
\text { Otobius megnini }\end{array}$ & $\begin{array}{l}\text { Garrapata de la estrella solitaria } \\
\text { Garrapata de cayena } \\
\text { Garrapata de la costa del golfo } \\
\text { Garrapata tropical } \\
\text { Garrapata de las montañas rocosas } \\
\text { Garrapata americana del perro } \\
\text { Garrapata británica del perro } \\
\text { Garrapata del erizo } \\
\text { Garrapata de la parálisis australiana } \\
\text { Garrapata de patas negras del oeste } \\
\text { Garrapata de la taiga } \\
\text { Garrapata de la oveja } \\
\text { Garrapata de patas negras } \\
\text { Garrapata amarilla del perro } \\
\text { Garrapata parda del perro } \\
\text { Garrapata espinosa de la oreja }\end{array}$ \\
\hline Porcinos & $\begin{array}{l}\text { Ornithodoros erraticus } \\
\text { Ornithodoros moubata } \\
\text { Dermacentor marginatus } \\
\text { Hyalomma lusitanicum } \\
\text { Rhipicephalus turanicus } \\
\text { Hyalomma marginatum }\end{array}$ & \\
\hline Aves & $\begin{array}{l}\text { Argas reflexus } \\
\text { Argas persicus } \\
\text { Argas sanchezi } \\
\text { Argas radiates } \\
\text { Argas neghmei } \\
\text { Haemaphysalis punctata } \\
\text { Hyalomma } \mathrm{sp} \\
\text { Ixodes ricinus } \\
\text { Rhipicephalus } \mathrm{sp} \\
\text { Amblyomma } \mathrm{sp}\end{array}$ & \\
\hline
\end{tabular}

${ }^{1}$ Cortinas y Jones, 2006; Kolonin 2008; Dantas-Torres 2010; Montasser 2010; Gunn y Pitt, 2012; Demeler et al., 2012; Zapata, 2012 


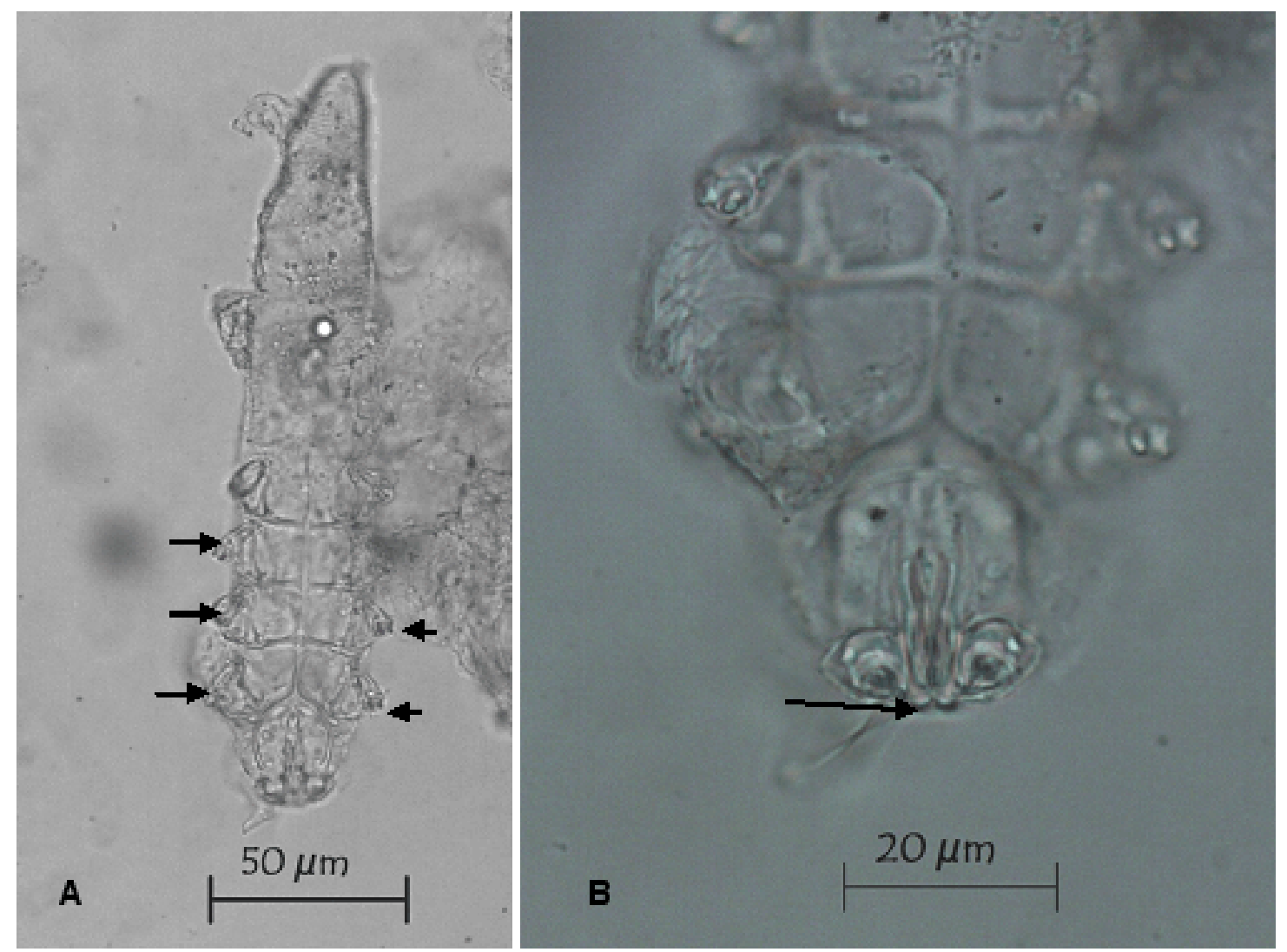

Figura 7. Demodex sp adulto. A. Patas cortas. 400x. B. Quelíceros. 1000x
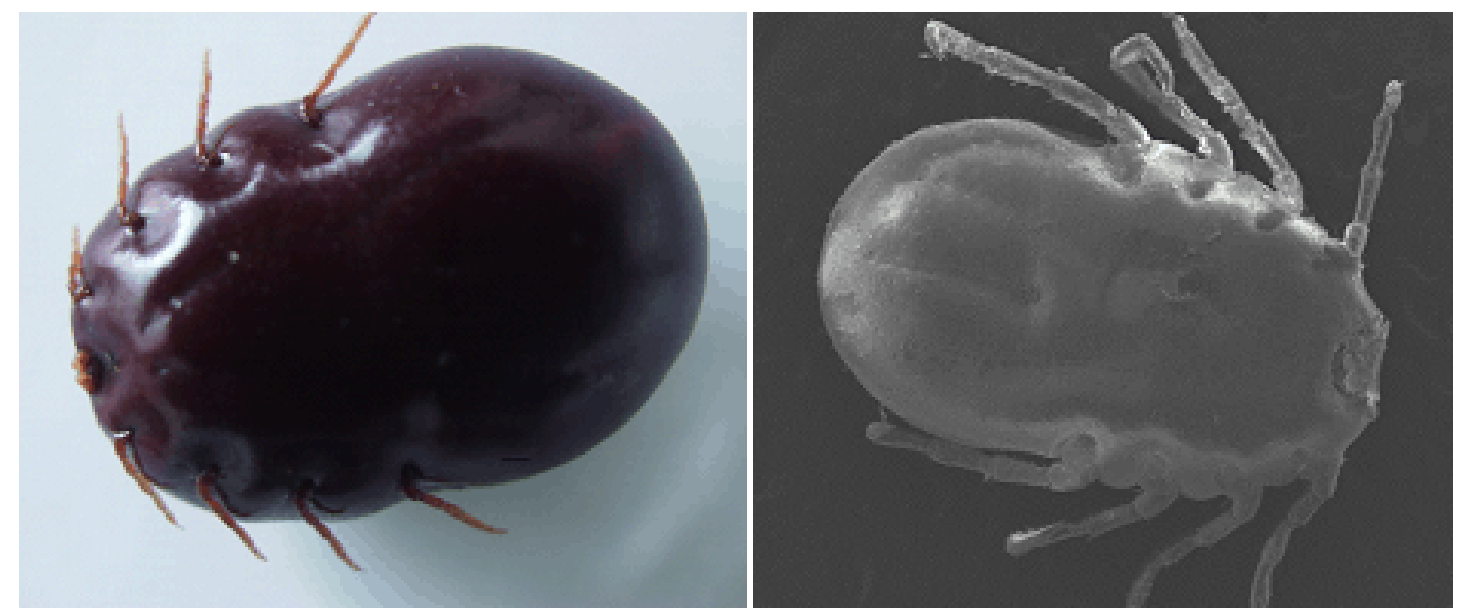

Figura 8. Rhipicephalus (Boophillus) sp. Hembra adulta ingurgitada 
y Jones, 2006; Stafford, 2007; Dantas-Torres 2010; Kaufman, 2010; Krem y Aspöck, 2012; Zapata, 2012).

Durante el desarrollo de las garrapatas se pueden observar cuatro estadios evolutivos: huevo, larva (6 patas), ninfas (8 patas) sexualmente inmaduras y adultos sexualmente maduros (8 patas). Esto último ocurre al desprenderse del hospedero y cuyos cambios son reconocidos como una metamorfosis incompleta (Cortinas y Jones, 2006). Luego de un periodo de alimentación de 7 a 12 días, la hembra adulta ingurgitada (llena de sangre), caen al suelo para realizar la oviposición (Fig. 8).

Las patas se unen al idiosoma por el primer segmento, denominado coxa (Fig. 9), donde se observan los espolones útiles para su identificación (Cordero del Campillo et al., 1999; Stafford, 2007; Bowman, 2009; Gunn y Pitt, 2012). Las patas están divididas en coxa, trocánter, fémur, patela, tibia, metatarso, tarso, ambulacro y uñas. En el tarso se localiza el órgano de Haller con varias setas o pelos (Figs. 9 y 10), cuya función es básicamente sensitiva, permitiéndoles percibir la temperatura, humedad, olores y vibraciones (Cordero del Campillo et al., 1999; Stafford, 2007).

El cuerpo de la garrapata adulta está constituido por la falsa cabeza, denominada capítulo o gnatosoma (Krem y Aspöck, 2012) y el idiosoma (podosoma y opistosoma) (Fig. 11) (Cordero del Campillo et al., 1999; Cortinas y Jones, 2006). El gnatosoma está formado por el conjunto de dos quelíceros con extremos aserrados, un hipostoma con presencia de estructuras denominadas dentículos $\mathrm{y}$ dos pedipalpos que difieren en la forma, dependiendo del género y especie (Fig. 12). Estas estructuras son utilizadas como clave taxonómica para su clasificación (Cordero del Campillo et al., 1999; Stafford, 2007; Krem y Aspöck, 2012).
El sistema respiratorio (traqueal) se abre al exterior en los orificios denominados espiráculos, que pueden tener una forma oval, redondeada o en forma de coma, y que se localizan a nivel del cuarto par de patas (Cordero del Campillo et al., 1999; Stafford, 2007).

Las garrapatas pertenecientes a la familia Ixodidade se denominan garrapatas duras, debido a que presentan un escudo duro (quitinoso) localizado en la parte dorsal del cuerpo; que en el caso de las hembras adultas, ninfas y larvas, ocupa el tercio anterior (Fig. 13), mientras en los machos adultos cubre toda la superficie. Las características morfológicas del escudo dependen del género, siendo en algunos casos ornamentados, lo que puede ayudar en la identificación (Cordero del Campillo et al., 1999; Cortinas y Jones, 2006; Stafford, 2007; Bowman, 2009; Gunn y Pitt, 2012). El capítulo se proyecta anteriormente y es fácilmente visible desde la parte superior en todos los estadios de desarrollo (Cordero del Campillo et al., 1999; Stafford, 2007; Gunn y Pitt, 2012).

Normalmente poseen ojos simples localizados en la superficie dorsal, a cada lado de los márgenes del escudo, aproximadamente a nivel del segundo par de patas (excepto los géneros Ixodes y Haemaphysalis) (Cordero del Campillo et al., 1999). En las garrapatas adultas, se observan dos aberturas en la cara ventral, la anterior es la genital (entre el segundo par de patas) y la posterior es la anal (Figs. 9 y 14). En las garrapatas del género Ixodes, en la parte frontal de la apertura anal se observa el surco anal con forma de U invertida, mientras en los otros géneros se encuentra por detrás de la apertura en forma de $\mathrm{Y}$ o ausente en otros casos (Cordero del Campillo et al., 1999; Stafford, 2007).

Otro rasgo importante es la presencia de festones (excepto en el género Ixodes), que corresponden a áreas rectangulares separadas por ranuras localizadas a los lados de la parte posterior del cuerpo de la garrapata (Stafford, 2007). 


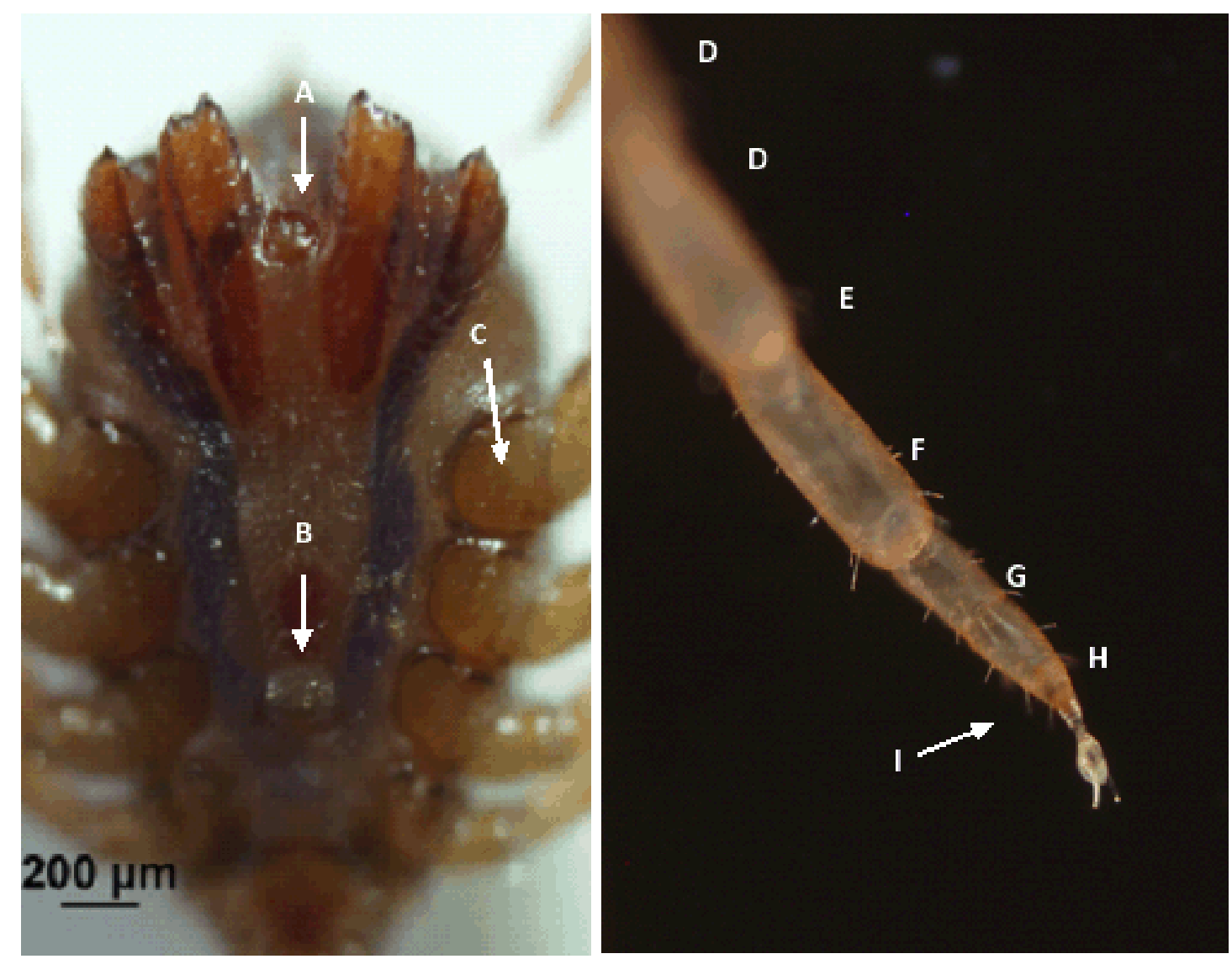

Figura 9. Ixodes sp. A. Poro anal; B. Poro genital; C. Coxa; D. Fémur; E. Patela; F. Tibia; G. Metatarso; H. Tarso; I. Seta

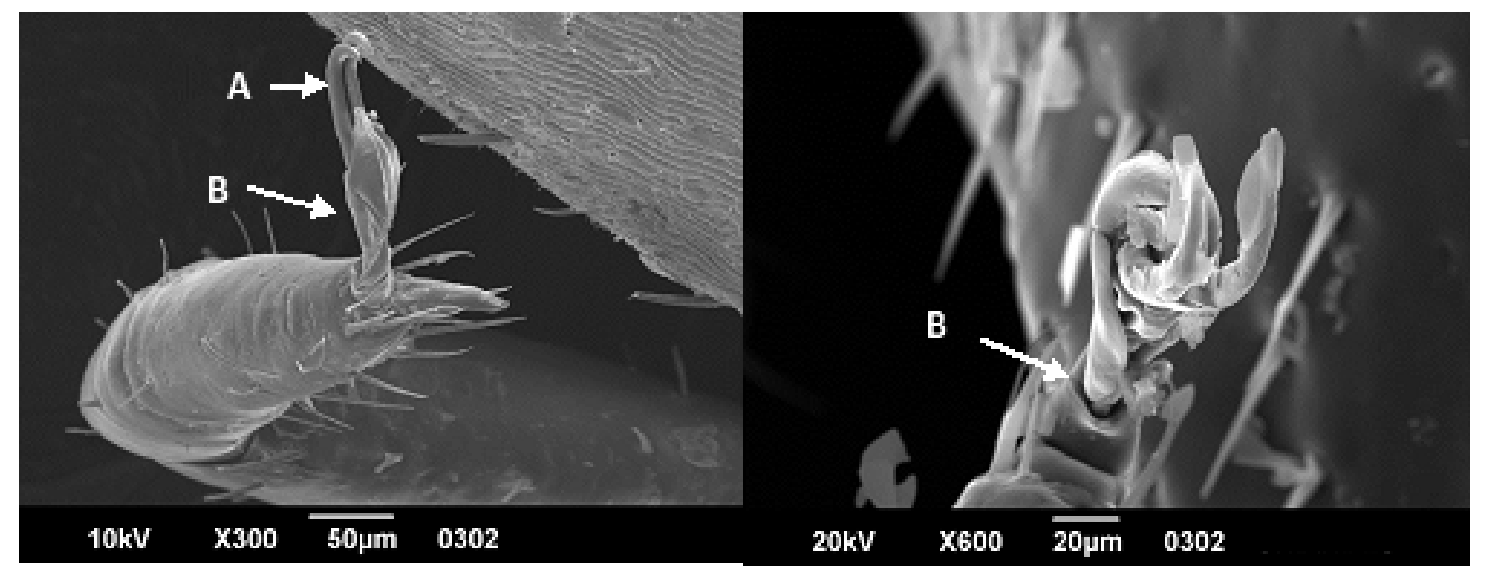

Figura 10. Microscopía electrónica de barrido (MEB) de las patas de la garrapata. A. Uñas o garras; B. Carúncula o ambulacro 


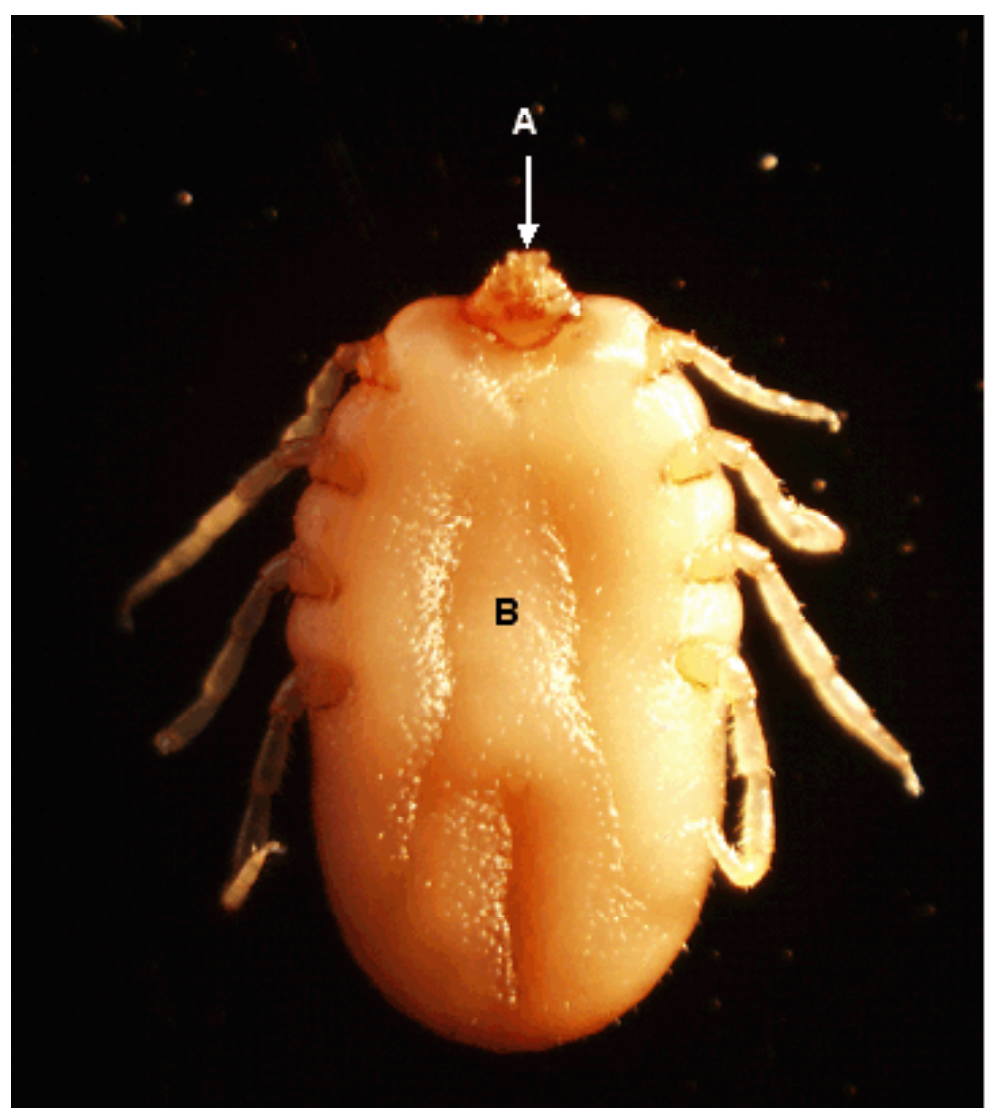

Figura 11. Rhipicephalus (Boophilus) sp. A. Capítulo o gnatosoma; B. 'Abdomen' o idiosoma

Las garrapatas de la familia Argasidae son clasificadas como garrapatas blandas, cuya principal característica es la ausencia de escudo en la superficie dorsal; así como la localización subterminal o ventral del capítulo en las adultas, lo que no permite su visualización desde la parte dorsal, y que en el caso de larvas y ninfas puede tener una localización terminal (Cordero del Campillo et al., 1999; Cortina y Jones, 2006; Stafford, 2007; Bowman, 2009; Montasser, 2010). En general, las garrapatas de esta familia son coriáceas, de tegumento rugoso, grisáceas y carecen de ojos (Stafford, 2007; Bowman, 2009). La cutícula está cubierta con espinas (Figs. 15 y 16) y el dimorfismo sexual se limita a leves diferencias en la apertura genital, donde en el macho es más pequeña y arqueada con presencia de un opérculo (Cordero del Campillo et al., 1999; Bowman, 2009).
Las garrapatas son fácilmente detectables sobre sus hospedadores, y pueden ser retiradas manualmente de la piel del hospedador; sin embargo, se debe tener en cuenta que las piezas bucales generalmente están firmemente incrustadas en la piel. Un método para desprender la garrapata es adicionando sobre ella un trozo de algodón empapado en anestésico o colocando cerca de ella un objeto caliente; asimismo, las que se encuentran en el pasto pueden obtenerse mediante el arrastre de un manto sobre el suelo. En forma similar a otros ectoparásitos, las características morfológicas son de gran importancia para su identificación (Fig. 15).

\section{Piojos}

Dentro de los insectos, los piojos pertenecen al Phylum Arthropoda, clase Insecta, 


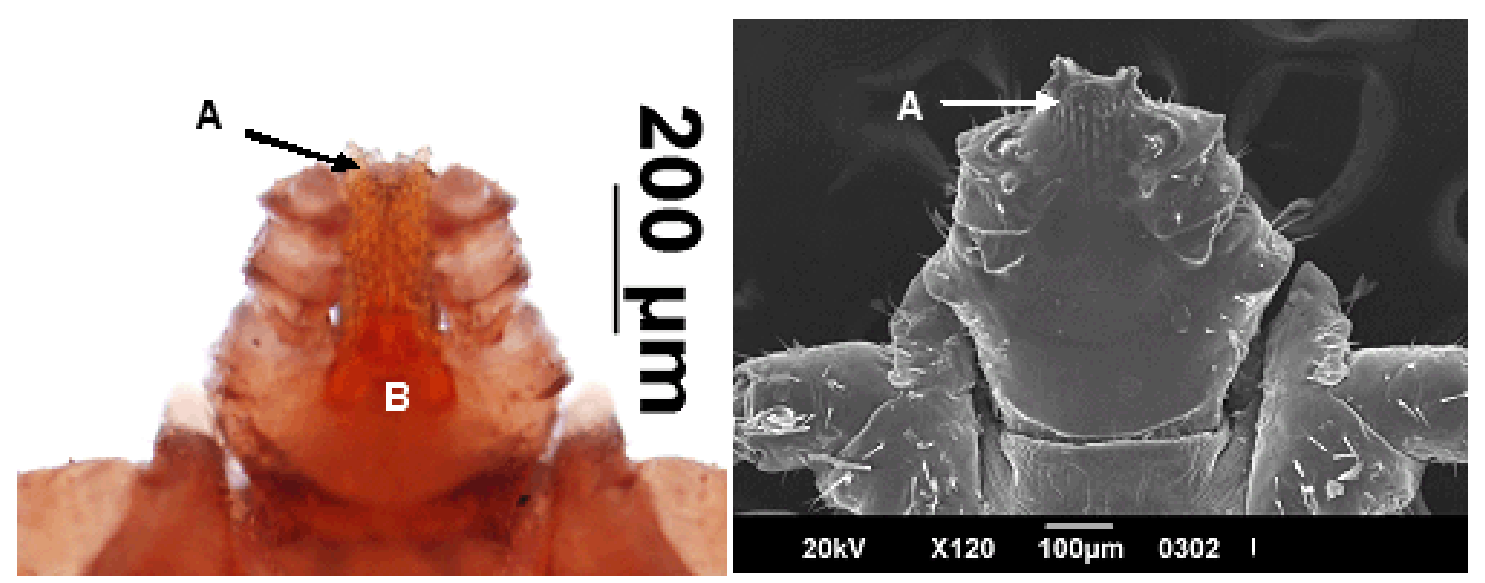

Figura 12. Gnatosoma. A. Palpos; B. Hipostoma dentado

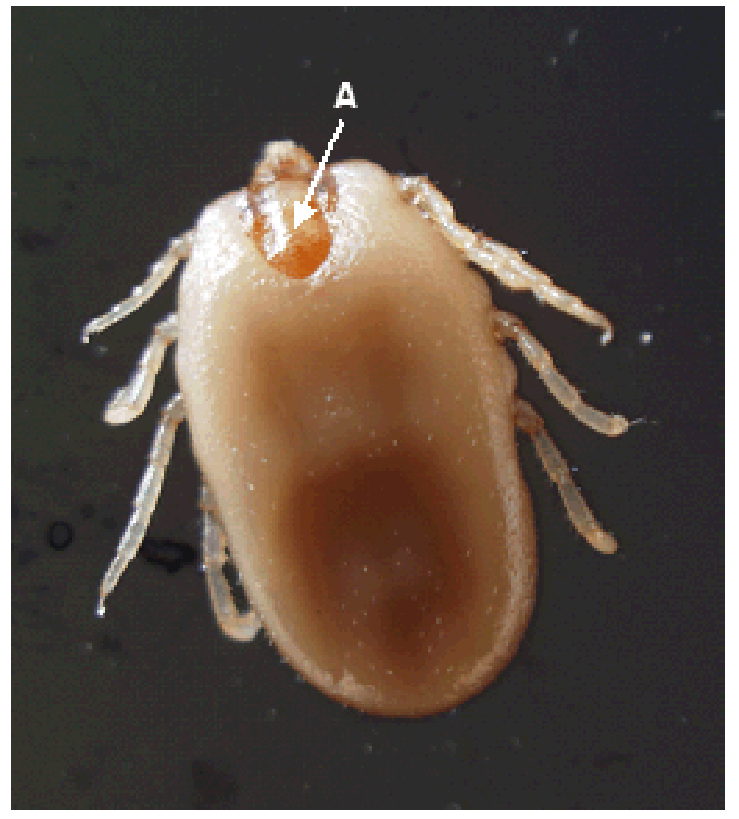

Figura 13. Escudo dorsal en una garrapata hembra (A)

subclase Pterigota, orden Phithiraptera (piojos), que a su vez se divide en dos subórdenes: Anoplura o «chupadores» y Mallophaga o «masticadores» (Cortina y Jones, 2006). Los Mallophaga se dividen en los órdenes Amblycera (7 familias), Ischnocera (3 familias) y Rhyncophthirina (1 familia), en tanto que los Anoplura están clasificados en varias familias, siendo las principales: Haematopinidae, Hoplopleuridae, Linognathidae, Pedicinidae y Polyplacidae (Mullen y Durden, 2002; Hellenthal y Price, 2009; Gunn y Pitt, 2012). Los Mallophaga, aunque son reconocidos como hospederos-específicos, parasitan 

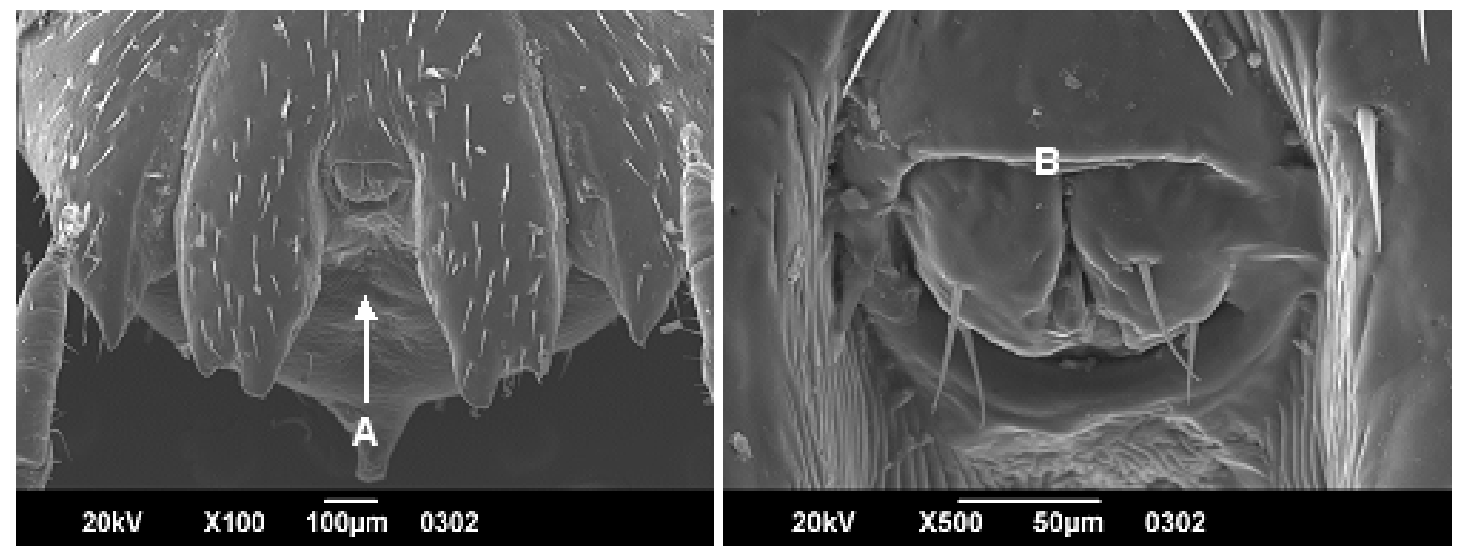

Figura 14. Microscopía electrónica de barrido (MEB). A. Poro anal; B. Acercamiento del poro anal

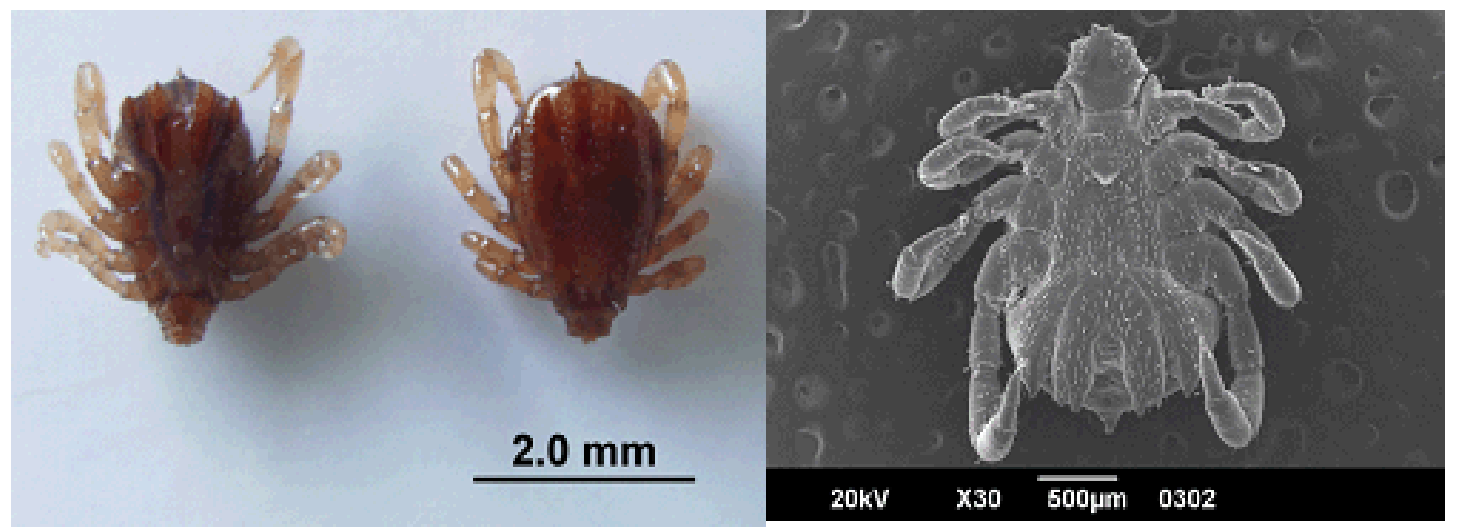

Figura 15. Vista dorsal y ventral de garrapatas Ixodes sp machos adultos

aves y mamíferos, mientras los Anoplura parasitan estrictamente mamíferos, algunos de ellos con localización específica en el hospedero (Cuadro 3) (Zajac y Conboy, 2012; Boyd y Reed, 2012).

Estos ectoparásitos realizan todo el ciclo de vida en el hospedero, donde dependen de condiciones medioambientales como temperatura y humedad. Las hembras sexualmente maduras realizan la oviposición, don- de las larvas son liberadas a través del opérculo. El primer estadio ninfal cumple con tres mudas o «instares», hasta convertirse en adulto (Hellenthal y Price, 2009; Boyd y Reed, 2012).

Los piojos chupadores (Anoplura) son grandes, de color rojo-gris, con el tórax más ancho que la cabeza, la cual tiene forma de flecha (Fig. 17). Además, tiene piezas bucales o probóscide (Fig. 18) con tres estiletes 

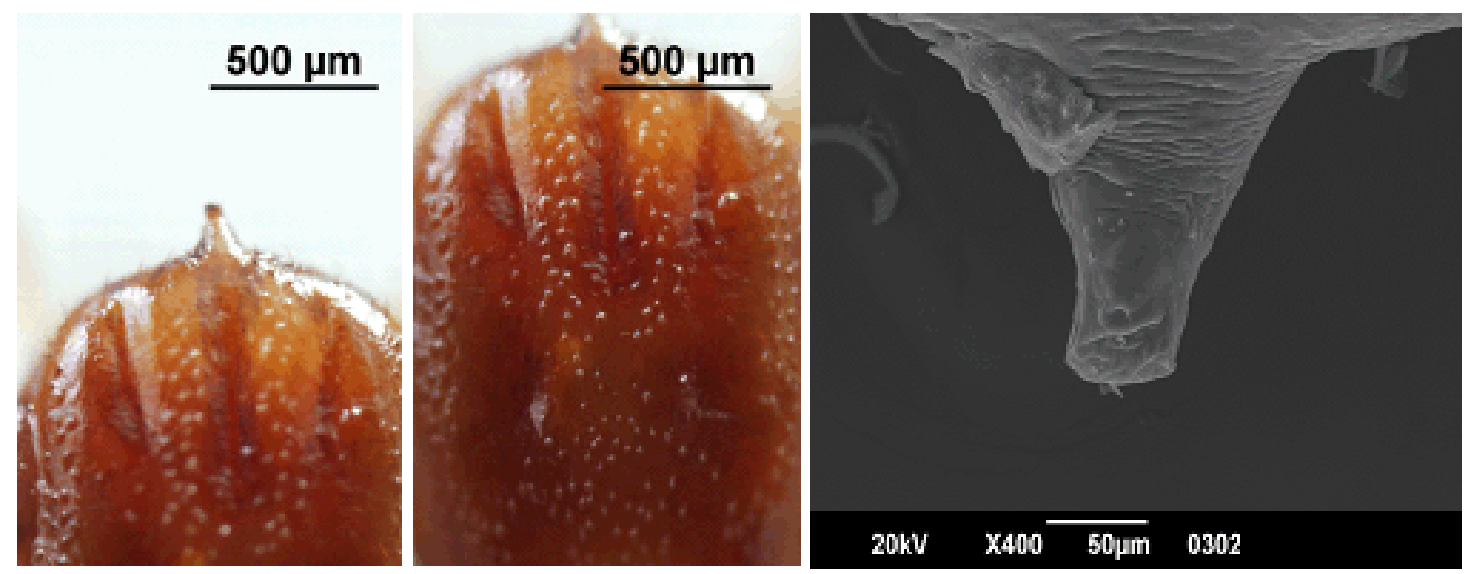

Figura 16. Espinas de la cutícula y extremo caudal de la garrapata

(Mullen y Durden, 2009; Hellenthal y Price, 2009) que les permiten penetrar la piel hasta encontrar sangre e introducirla como una bomba de succión por el canal hipofaríngeo (Krenn y Aspöck, 2012). Estos estiletes pueden retraerse en periodos de no alimentación.

Los piojos masticadores (Mallophaga) son pequeños, amarillos, con la cabeza más ancha que el tórax, y utilizan sus mandíbulas para morder plumas, caspa, piel e incluso, algunos muerden a tal profundidad que pueden obtener secreciones dérmicas y sangre (Hellenthal y Price, 2009; Boyd y Reed, 2012; Gunn y Pitt, 2012).

El tórax de los Phithiraptera está generalmente dividido en dos o tres partes; sin embargo, en los Anoplura parecen estar fusionados (Fig. 19) (Muller y Durden, 2009). Los tres pares de patas terminan en garras tibio-tarsales en forma de gancho (Fig. 20), lo que les permite anclarse al pelo del hospedero (Ligth et al., 2010; Krenn y Aspöck, 2012), especialmente los Mallophaga en las aves o en aquellos hospederos de movimiento rápido.

Los huevos, denominados «liendres», generalmente adheridos al pelo o plumas del hospedero (Muller y Durden, 2009; Hellenthal y Price, 2009; Gunn y Pitt, 2012), son de forma ovalada y puntas redondeadas con opérculo delgado, que permite el intercambio de aire a través de poros llamados micrópilos (Fig. 21) (Muller y Durden, 2009).

La detección de estos ectoparásitos requiere de un examen minucioso. Las liendres se encuentran generalmente adheridas a los pelos o plumas (Fig. 22), y pueden extraerse al cepillar o cortar el pelo o plumas (Zajac y Conboy, 2012).

\section{Pulgas}

Estos ectoparásitos son insectos pequeños de 1 a $10 \mathrm{~mm}$ de longitud, del Phylum Arthropoda, clase Insecta, orden Siphonaptera, familias Pulicidae y Tungidae, con varios géneros y más de 2500 especies descritas en el mundo (Cordero del Campillo et al., 1999; Muller y Durden, 2009; Gunn y Pitt, 2012; Zajac et al., 2012). Las más comunes se presentan en el Cuadro 4.

Las infestaciones causadas por estos ectoparásitos se asocian con pérdida de sangre, hipersensibilidad y transmisión de parásitos como Hymenolepsis nana, Hymenolepsis diminuta y Dipylidium caninum (Botero et al., 1992), y enfermedades 
Cuadro 3. Algunas especies reportadas en la literatura científica ${ }^{1}$ de Phithiraptera y su respectiva ubicación en hospederos animales

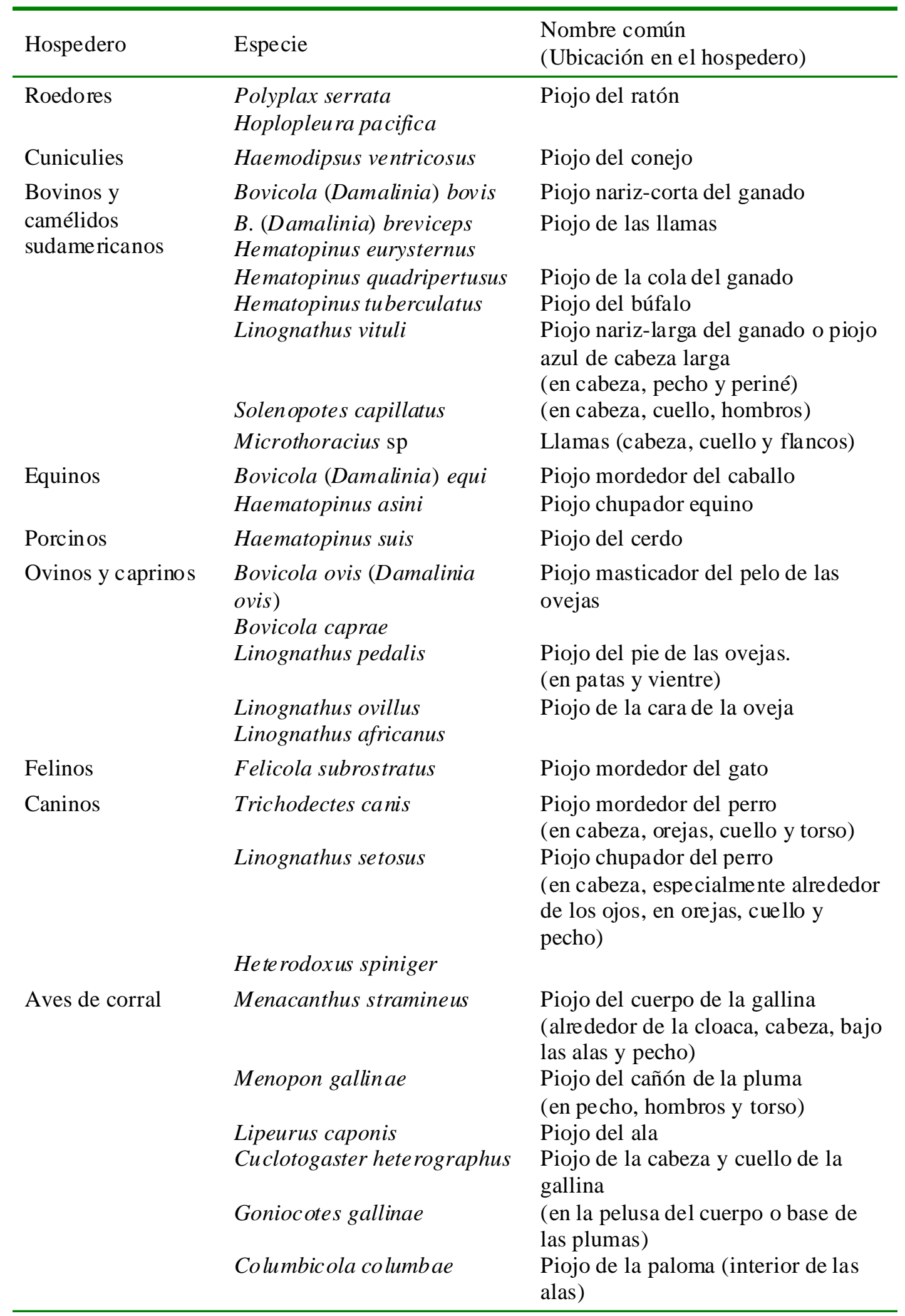

${ }^{1}$ Bergvall, 2005; Cortinasy Jones, 2006; Demeler et al., 2012; Figueiredo et al, 2013 

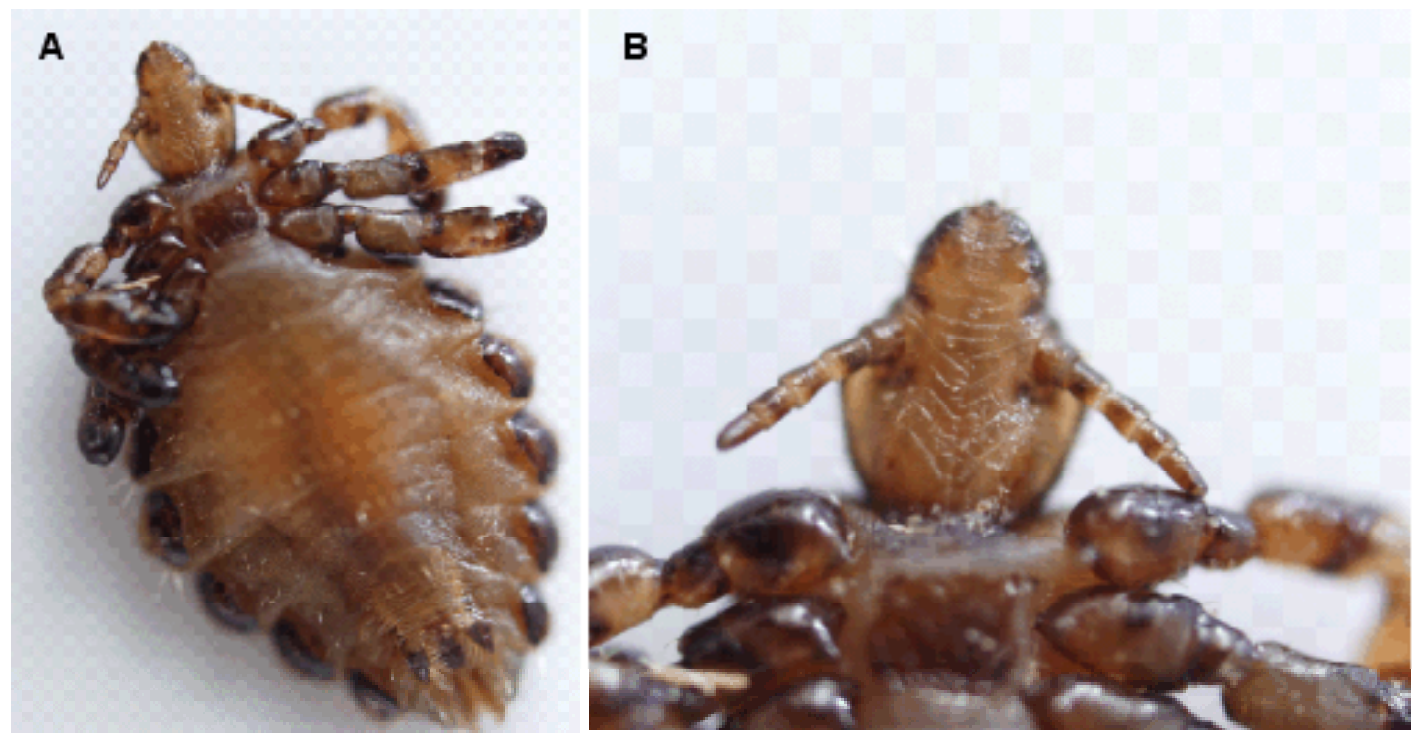

Figura 17. Anoplura adulto. A. Morfología macroscópica del cuerpo; B. Morfología de la cabeza en forma de flecha

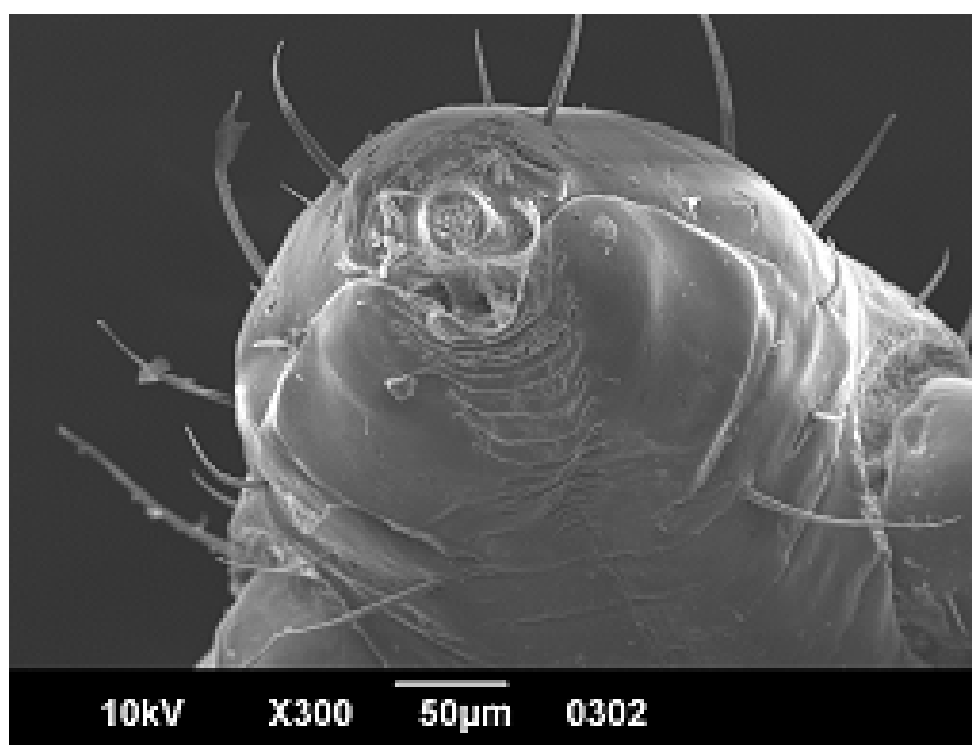

Figura 18. Microscopía electrónica de barrido (MEB). Piezas bucales de un Anoplura adulto 

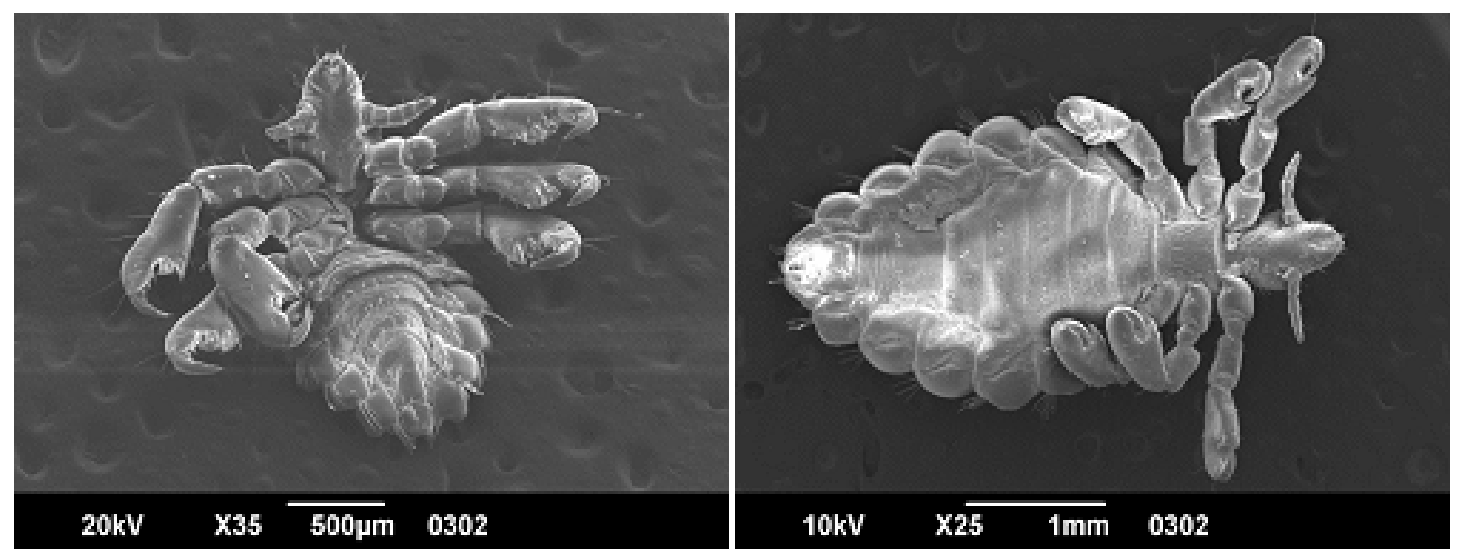

Figura 19. Microscopía electrónica de barrido (MEB). Anoplura adulto (Haematopinus tuberculatus)
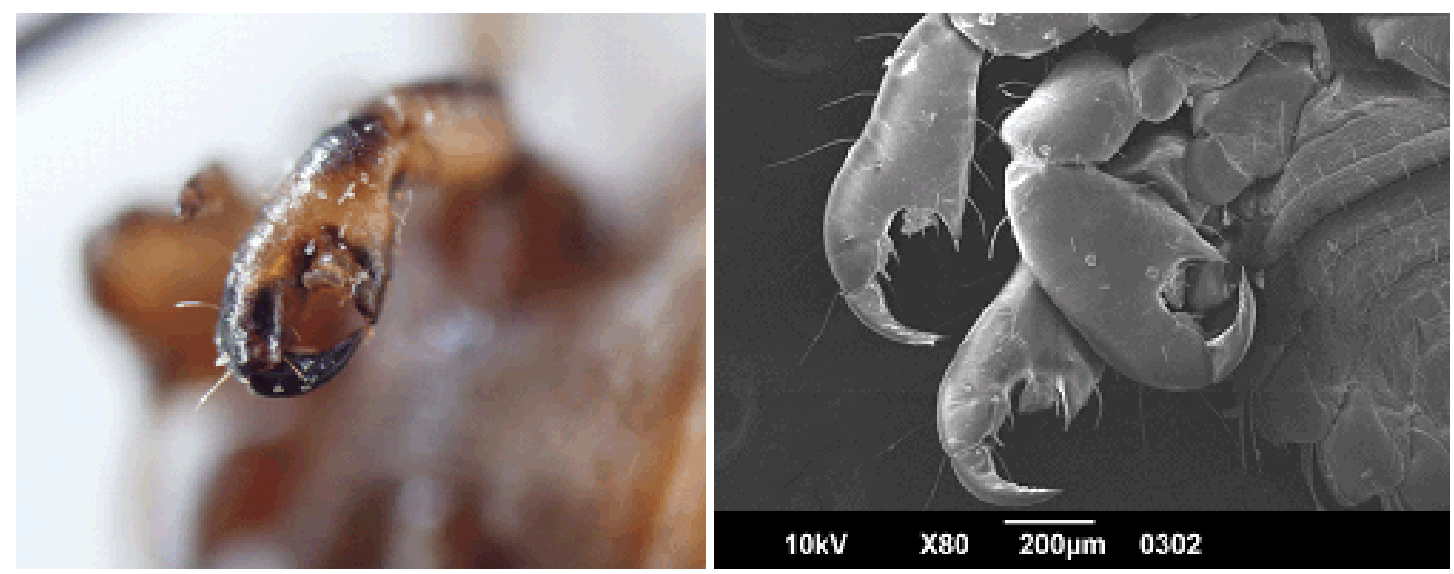

Figura 20. Garras tibio-tarsal de las patas de un Anophlura (Haematopinus tuberculatus)

bacterianas como borreliosis, bartonellosis, rickettsiosis y micoplasmosis (Orozco et al., 2008; Krem y Aspöck, 2012; Zapata, 2012; Lawrence et al., 2015).

Su ciclo de vida consta de huevo, tres instares larvales, pupa y adulto; es decir, realiza una metamorfosis completa que puede prolongarse durante tres semanas (Orozco et al., 2008; Muller y Durden, 2009; Gunn y Pitt, 2012). El desarrollo del ciclo completo puede variar según la temperatura, por ejemplo, para $C$. felis es de 40 días a $15^{\circ} \mathrm{C}$ o de 13 días a $30^{\circ} \mathrm{C}$ (Cordero del Campillo et al., 1999). Los huevos son lisos y se encuentran generalmente en las camas y lugares donde el animal permanece más tiempo (Orozco et al., 2008). La fase de larva no es parásita y usualmente se alimenta de detritus provenientes del hospedador, aunque algunas especies requieren de sangre para su crecimiento, la que obtienen de heces de pulgas adultas. Una 

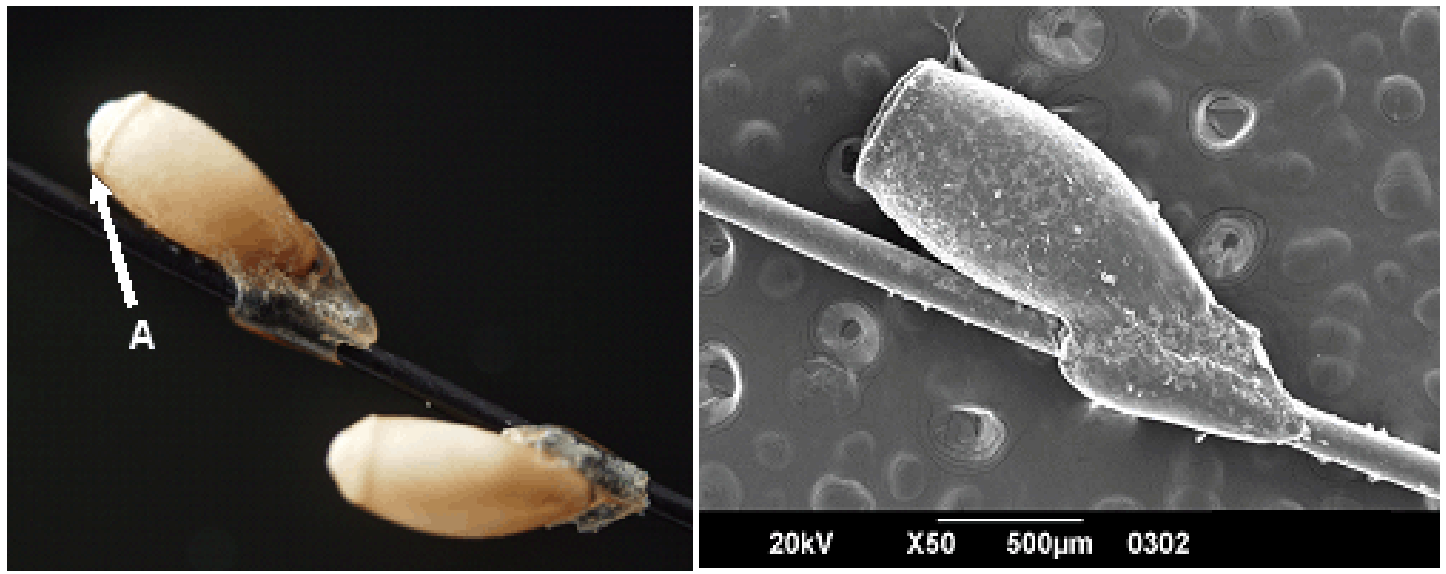

Figura 21. Huevos (liendres) adheridos a un pelo de búfalo. A. Opérculo

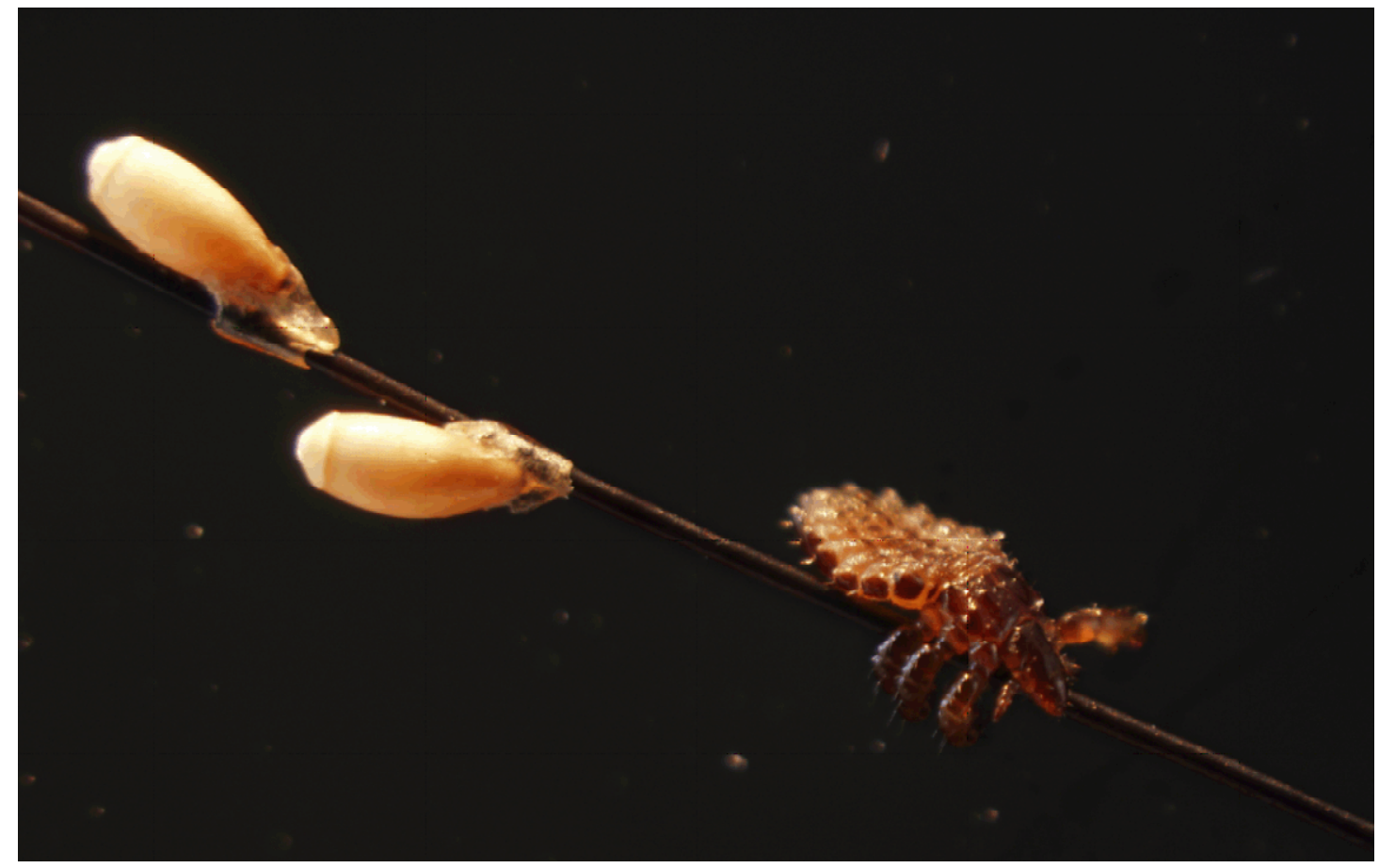

Figura 22. Haematopinus tuberculatus adulto y huevos (liendres) adheridos a un pelo de búfalo

vez completado el estadio de instar, la larva teje un capullo y entra en una etapa de prepupa, para luego mudar a pupa (Muller y Durden, 2009; Gunn y Pitt, 2012). La emergencia del adulto del pupario se lleva a cabo como respuesta a determinadas vibraciones o a un aumento del $\mathrm{CO}_{2}$. Sin estos estímulos de emergencia, las pulgas pueden permanecer quiescentes durante mucho tiempo (hasta 234 días para C. canis). 
Cuadro 4. Algunas especies de Siphonaptera reportadas en la literatura científica ${ }^{1}$ y su respectivo hos pedero animal

\begin{tabular}{lll}
\hline Hospedero & Ectoparásito & Nombre común \\
\hline Felinos & Ctenocephalides felis & Pulga del gato (y en perros) \\
Caninos & Ctenocephalides canis & Pulga del perro \\
& Pulex simulans & Pulga del perro \\
Roedores & Xenopsylla cheopsis & Pulga del ratón de oriente \\
& Nosopsyllus fasciatus & Pulga de la rata norteña \\
& Oropsylla montana & Pulga de la rata norteamericana \\
& Cediopsylla simplex & Pulga del conejo \\
Aves de corral & Echidnophaga gallinacea & Pulga de la gallina \\
Rumiantes, porcinos, & Tunga trimamillata & Nigua, chica, pique* \\
equinos & & \\
Humano & Pulex irritans & Pulga del hombre \\
\hline
\end{tabular}

${ }^{1}$ Orozco et al. 2008; Pampliglione et al., 2009*; Gunn y Pitt, 2012; Zapata, 2012

Los adultos permanecen en su hospedero, pero usualmente se mueven alrededor de este para alimentarse. Su forma aplanada les permite arrastrarse fácilmente entre los pelos y plumas, y pueden moverse entre hospederos cercanos. Asimismo, pueden correr muy rápido y sus largas patas posteriores le permiten realizar saltos hasta de $30 \mathrm{~cm}$ de largo. Los adultos solo emergen de sus puparios hasta que detectan que el hospedador ha ingresado a su nido, lo que explica que en algunos domicilios que han permanecido desocupados por mucho tiempo, los nuevos ocupantes comienzan a «vivir con pulgas» (ESCCAP, 2012; Gunn y Pitt, 2012; Lawrence et al., 2015).

Los adultos son aplanados lateralmente e infectan a la mayoría de mamíferos y aves, produciendo diferentes tipos de reacciones alérgicas (Rodríguez, 2002).

Su color café oscuro los mimetiza en el pelo del animal y su capacidad de salto las hace difíciles de atrapar. Carece de ojos compuestos aunque tienen un grupo de ocelos que les permite detectar cambios de intensidad de luz (Gunn y Pitt, 2012), la cual tienden a evitar (Fig. 23). Su aparato bucal posee un labio y palpos labiales diseñados para penetrar la piel y alimentarse de sangre del hospedero, que es conducida hacia el interior a través de un canal denominado epifaringe (Rodríguez, 2002; Krenn y Aspöck, 2012).

Muchas especies presentan cerdas dispuestas hacia atrás y espinas en fila denominadas ctenidios, lo que facilita su agarre al pelo o plumas dificultando así su extracción. En el extremo posterior de la superficie dorsal se encuentra el pigidio, una estructura sensorial que detecta vibraciones (Figs. 23 y 24), útil para escapar de posibles depredadores.

La cabeza de $C$. canis está fuertemente redondeada en su región anterior, mientras que en $C$. felis es alargada (Linardi y Costa, 2012). Los ctenidios genales tienen una longitud aproximada de la mitad de la longitud de la segunda espina. En C. canis, la tibia de las patas posteriores normalmente tiene las dos últimas setas laterales interiores separadas y casi de la misma longitud; en tanto que en $C$. felis, la tibia del tercer par de patas 

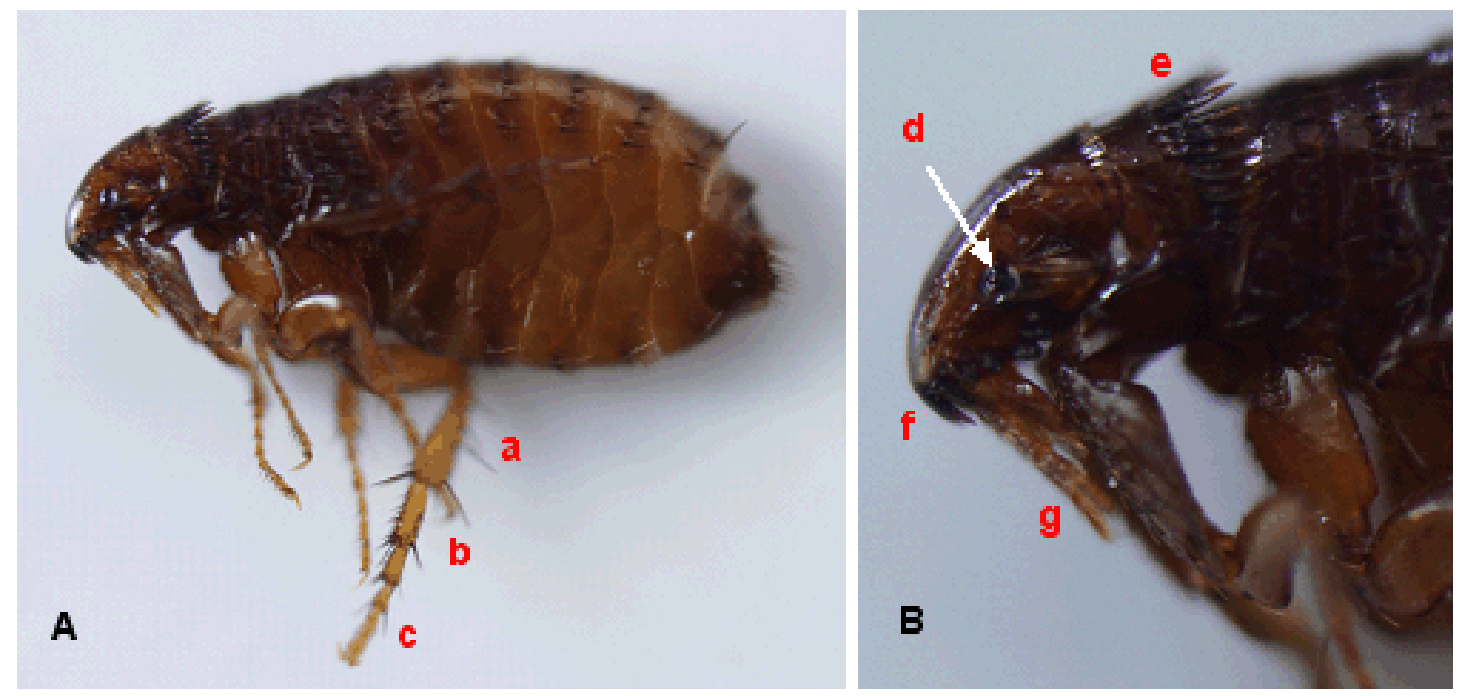

Figura 23. Ctenocephalides felis. A. Morfología macroscópica del cuerpo: (a) Fémur; (b) Tibia; (c) Tarso. B. Morfología de la cabeza: (d) Presencia de ocelos; (e) Ctenidio pronotal; (f) Ctenidio genal; (g) palpos del aparato bucal
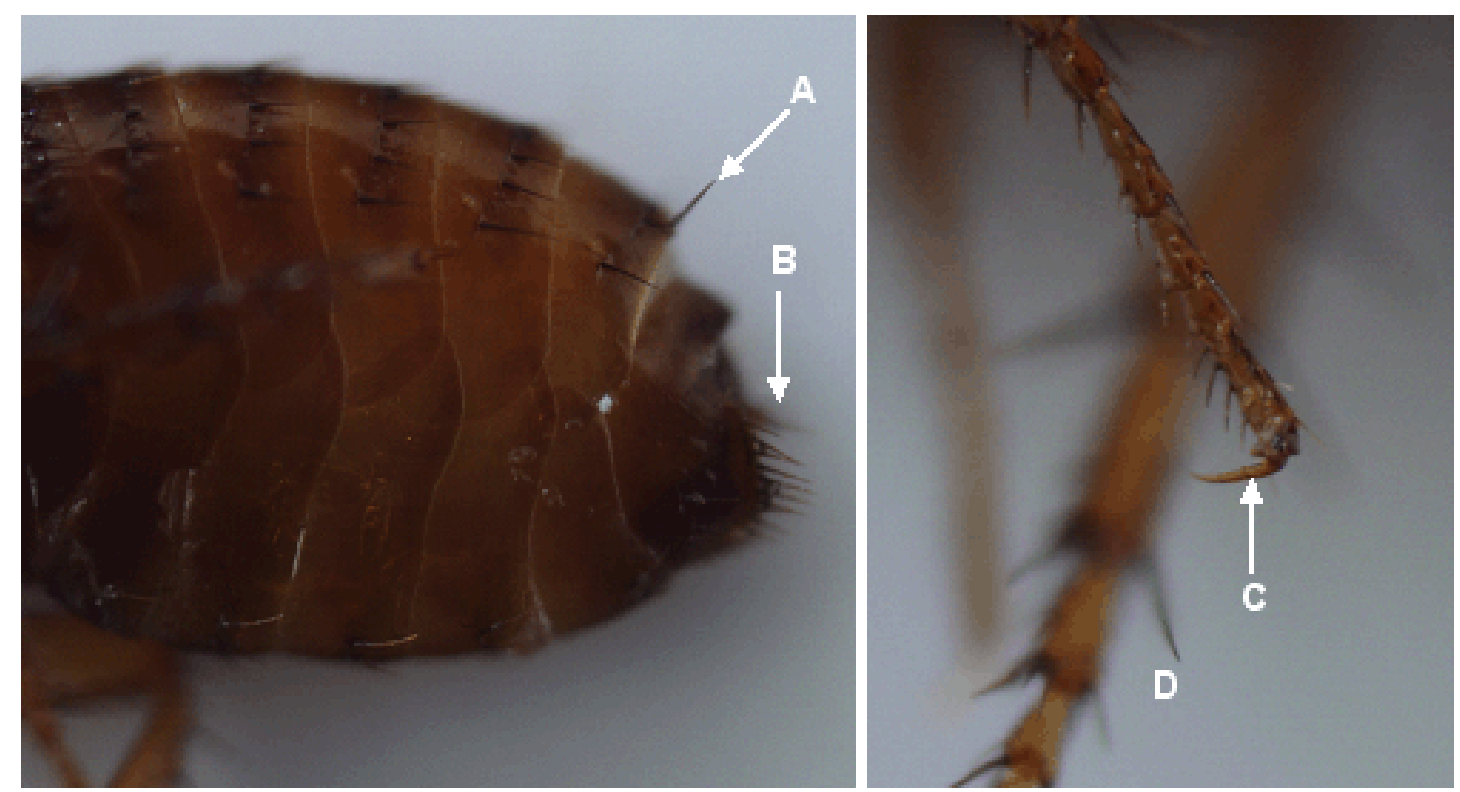

Figura 24. Ctenocephalides felis. A. Seta antesensilial; B. Pigidio en el abdomen; C. Uña; D. Setas

normalmente tiene una sola seta lateral inferior interna (Cordero del Campillo et al., 1999).

La recolección de las pulgas puede realizarse manualmente. Para su identificación se debe tener en cuenta sus características morfológicas, aunque el hallazgo de heces sobre el pelo puede servir como confirmación de la infestación. Las heces de las pulgas se caracterizan por aparecer como pequeños fragmentos que al entrar en contacto con un tejido o algodón húmedo adquieren 
una coloración rojiza por los restos de sangre digerida (Muller y Durden, 2009).

\section{Literatura Citada}

1. Balashov YS. 2006. Types of parasitism of Acarines and insects on terrestrial vertebrates. Entomol Rev 86: 957-971. doi: 10.1134/S0013873806080112

2. Ballweber LR. 2006. Diagnostic methods for parasitic infections in livestock. Vet Clin North Am Food Anim Pract 22: 695-705. doi: 10.1016/ j.cvfa.2006.06.001

3. Bergvall K. 2005. Advances in acquisition, identification, and treatment of equine ectoparasites. Clin Tech Equine Pract 4: 296-301. doi:10.1053/ j.ctep.2005.10.003

4. Bowman DD. 2009. Georgi's parasitology for veterinarians. $9^{\text {th }}$ ed. USA: Saunders. $451 \mathrm{p}$.

5. Boyd BM, Reed DL. 2012. Taxonomy of lice and their endosymbiotic bacteria in the post-genomic era. Clin Microbiol Infect 18: 324-331. doi: 10.1111/j.14690691.2012.03782.x

6. Cordero del Campillo M, Rojo FA, Martínez AR, Sánchez C, Hernández S, Navarreta J, Díez P, et al. 1999. Artrópodos. En: Parasitología Veterinaria. 2a ed. México: McGraw-Hill Interamericana. p 134-151.

7. Cortinas R, Jones $C .2006$. Ectoparasites of cattle and small ruminants. Vet Clin North Am Food Anim Pract 22: 673-693. doi: 10.1016/ j.cvfa.2006.06.003

8. Curtis CF. 2001. Diagnostic techniques and sample collection. Clin Tech Small Anim Pract 16: 199-206. doi: 10.1053/ svms.2001.26998

9. Dantas-Torres F. 2010. Biology and ecology of the brown dog tick, Rhipicephalus sanguineus. Parasite Vector 3: 26. doi: 10.1186/1756-3305-3-26

10. Demeler J, Schein E, von SamsonHimmelstjerna G. 2012. Advances in laboratory diagnosis of parasitic infections of sheep. Vet Parasitol 189: 52-64. doi:10.1016/j.vetpar.2012.03.032

11. [ESCCAP] European Scientific Counsel Companion Animal Parasites. 2012. Control of ectoparasites in dogs and cats. ESCCAP Guideline 03. $2^{\text {nd }}$ ed. [Internet]. Disponible en: http:/ /www.esccap.org/uploads/file/ ESCCAP\% 20Guidelines\%20GL3\% 20Final\%2 029June2012(2).pdf

12. Figueiredo MAP, Silva DF, Manrique WG, Guerra MSNC. 2013. Infestación y distribución de Haematopinus tuberculatus en bubalinos de São Luís, Estado do Maranhão, Brasil. Biologist (Lima) 11(1): 167-172.

13. Flamini G. 2003. Acaricides of natural origin, personal experiences and review of literature (1990-2001). Studies Nat Products Chem 28: 381-451. doi:10.1016/ S1572-5995(03)80146-1

14. George DR, Finn RD, Graham KM, Mul MF, Maurer V, Moro CV, Sparagano OAE. 2015. Should the poultry red mite Dermanyssus gallinae be of wider concern for veterinary and medical science? Parasit Vectors 8: 178188. doi:10.1186/s13071-015-0768-7

15. Gunn A, Pitt SJ. 2012. Artrhropod parasites. In: Parasitology, an integrated approach. UK: Wiley-Blackwell. p 137179.

16. Hellenthal RA, Price RD. 2009. Phthiraptera: chewing and sucking lice. In: Encyclopedia of insects. $2^{\text {nd }}$ ed USA: Academic Press. p 777-780.

17. Hernández MMA, Avello OE, Peña RFI, Lazo PL. 2010. Valoración epidemiológica de la sarna en canidos atendidos en una clínica veterinaria del municipio de Ranchuelo. REDVET 11 (03B). http://www.veterinaria.org/revistas/redvet/n030310B/0310B_DS17.pdf

18. Iraola $V$. 1998. Introducción a los ácaros (I): Descripción general y principales grupos. Bol S.E.A. No. 23. p 1319. [Internet]: Disponible en: http:// www.sea-entomologia.org/PDF/BOLETIN_23/B23-002-013.pdf 
19. Kaufman WR. 2010. Ticks: physiological aspects with implications for pathogen transmission. Ticks Tick Borne Dis 1: 11-22. doi: 10.1016/j.ttbdis. 2009. 12.001

20. Kolonin GV. 2008. Birds as hosts of Ixodid ticks (Acarina, Ixodidae). Entomol Rev 88: 1012-1015. doi: 10.1134/ S0013873808080150

21. Krenn HW, Aspöck H. 2012. Form, function and evolution of the mouthparts of blood-feeding Arthropoda. Arthropod Struct Dev 41: 101-118. doi: 10.1016/ j.asd.2011.12.001

22. Lawrence AL, Hii SF, Jirsová D, Panáková L, Ionica AM, Gilchrist K, Modrý D, et al. 2015. Integrated morphological and molecular identification of cat fleas (Ctenocephalides felis) and dog fleas (Ctenocephalides canis) vectoring Rickettsia felis in central Europe. Vet Parasitol 210: 215-223. doi: 10.1016/j.vetpar.2015.03.029

23. Levot G. 2000. Resistance and the control of lice on humans and production animals. Int J Parasitol 30: 291-297. doi: 10.1016/S0020-7519(99)00203-9

24. Light JE, Smith VS, Allen JM, Durden LA, Reed DL. 2010. Evolutionary history of mammalian sucking lice (Phthiraptera: Anoplura). BMC Evol Biol 10: 292. doi: 10.1186/1471-2148-10-292

25. Linardi PM, Costa JL. 2012. Ctenocephalides felis felis vs. Ctenocephalides canis (Siphonaptera: Pulicidae): some issues in correctly identify these species. Rev Bras Parasitol Vet 21: 345-354. doi: 10.1590/ S1984-29612012000400002

26. Mapstone SC, Beasley A, Wall R. 2002. Structure and function of the gnathosoma of the mange mite, Psoroptes ovis. Med Vet Entomol 16: 378-385. doi: 10.1046/j.13652915.2002.00387.x

27. Montasser AA. 2010. The fowl tick, Argas (Persicargas) persicus (Ixodoidea: Argasidae): Description of the egg and redescription of the larva by scanning electron microscopy. Exp Appl Acarol 52: 343-361. doi: 10.1007/s10493-010-9377-5

28. Mullen G, Durden L. 2009. Medical and veterinary entomology. $2^{\text {nd }}$ ed. USA: Academic Press. 627 p.

29. Orozco JA, Sánchez MS, Jaramillo M, Hoyos LM. 2008. Frecuencia de Ctenocephalides canis y Ctenocephalides felis obtenidas de caninos infestados naturalmente en el valle de Aburrá. Rev CES Med Vet Zootec 3(2): 73-77.

30. Pampliglione S, Fioravanti ML, Gustinelli A, Onore G Mantovani B, Luchetti A, Trentini M. 2009. Sand flea (Tunga spp.) infections in humans and domestic animals: state of the art. Med Vet Entomol 23: 172-186. doi: 10.1111/ j.1365-2915.2009.00807.x

31. Saari S AM, Juuti KH, Palojärvi JH, Väisänen KM, Rajaniemi RL, Saijonmaa-Koulumies LE. 2009. Demodex gatoi-associated contagious pruritic dermatosis in cats - a report from six households in Finland. Acta Vet Scand 51: 40. doi: 10.1186/1751-0147-51-40

32. Stafford K. 2007. Tick management handbook. USA: The Connecticut Agricultural Experiment Station. [Internet]. Disponible en: http:// es.scribd.com/doc/83993049/4/TickMorphology

33. Wall $R$. 2007. Ectoparasites: future challenges in a changing world. Vet Parasitol 148: 62-74. doi: 10.1016/ j.vetpar.2007.05.011

34. Zajac AM, Conboy GA. 2012. Diagnosis of arthropod parasites. In: Veterinary clinical parasitology. $8^{\text {th }}$ ed. UK: Wiley-Blackwell. p 217-303.

35. Zapata R. 2012. Artrópodos como ectoparásitos y vectores de microorganismos relacionados con el proceso de infección - salud - enfermedad en animales de producción, animales de compañía y humanos. Hechos Microbiológicos 3(1): 63-66. 